\title{
One-dimensional haemodynamic modelling and wave dynamics in the entire adult circulation
}

\author{
Jonathan P. Mynard, Joseph J. Smolich \\ Heart Research, Clinical Sciences, Murdoch Childrens Research Institute; and \\ Department of Paediatrics, University of Melbourne, \\ Parkville, Victoria, Australia
}

Abbreviated Title: 1D modelling and waves in the entire adult circulation

Corresponding Author:

Jonathan P. Mynard

Heart Research, Clinical Sciences, Murdoch Childrens Research Institute 50 Flemington Rd. Parkville, VIC, 3052, Australia

Phone: +6139936 6038

E-mail: jonathan.mynard@mcri.edu.au 


\section{Abstract}

One-dimensional (1D) modelling is a powerful tool for studying haemodynamics; however, a comprehensive 1D model representing the entire cardiovascular system is lacking. We present a model that accounts for wave propagation in anatomically realistic systemic (including coronary and cerebral) arterial/venous networks, pulmonary arterial/venous networks and portal veins. A lumped parameter (OD) heart model represents cardiac function via a time-varying elastance and source resistance, and accounts for mechanical interactions between heart chambers mediated via pericardial constraint, the atrioventricular septum and atrioventricular plane motion. A non-linear windkessel-like OD model represents microvascular beds, while specialised OD models are employed for the hepatic and coronary beds. Model-derived pressure and flow waveforms throughout the circulation are shown to reproduce the characteristic features of published human waveforms. Moreover, wave intensity profiles closely resemble available in vivo profiles. Forward and backward wave intensity is quantified and compared along major arteriovenous paths, providing insights into wave dynamics in all of the major physiological networks. Interactions between cardiac function/mechanics and vascular waves are investigated. The model will be an important resource for studying the mechanics underlying pressure/flow waveforms throughout the circulation, along with global interactions between the heart and vessels under normal and pathological conditions.

Key terms: blood flow, systemic, pulmonary, coronary, portal, arteries, veins, cardiac chamber interactions, wave intensity analysis 


\section{Introduction}

The cardiovascular system is composed of many interdependent components. From a purely mechanical point of view, its performance is determined by a complex interplay between the contractility, preload and afterload of the four heart chambers, mechanical interactions between heart chambers, and the distributed impedance properties of the respective vascular networks. To gain insights into these interactions, analytical tools for studying the origins and determinants of blood pressure and flow waveforms are of utmost importance. One such tool is one-dimensional (1D) computational modelling, which enables in silico prediction of these waveforms in simulated vascular networks. ${ }^{1-12}$ Another is wave intensity analysis, which can be used to delineate mechanisms underlying the shape of pressure/flow waveforms and may be applied to both in vivo and model-derived data. ${ }^{13-22}$

The majority of 1D blood flow models in the literature have been open-loop and have focused on the systemic arteries, often with a prescribed aortic inflow. ${ }^{2,7,9}$ Some investigators have coupled relatively simple cardiac models to open-loop 1D arterial models ${ }^{1}$ or to closed-loop circulation models in which lumped parameter (OD) methods are used for some of the major networks (often the systemic veins and/or pulmonary circulation). ${ }^{3,23,24}$ Others have focused primarily on modelling the heart, investigating valve function, atrioventricular flow and inter-chamber interactions, ${ }^{25-28}$ without including anatomically-based vascular models. However, there is currently no comprehensive 1D model of the entire cardiovascular system that includes anatomically realistic 1D vascular networks in all major regions of the circulation, coupled to a OD heart model that accounts for major inter-chamber interactions. Such a model would be useful for studying wave dynamics throughout the circulation, along with global haemodynamic interactions between 
the heart and different vascular regions. It would also provide a useful framework for studying a wide range of questions related to cardiovascular disease, including various forms of congenital heart disease and associated palliations in which global interactions are likely to be of crucial importance.

The main goals of this paper were therefore to 1) describe such a model, 2) check the consistency of model-generated pressure/flow waveforms with published data, 3) conduct a preliminary analysis of wave intensity patterns throughout the circulation, and 4) investigate some of the complex interactions between cardiac chamber function and vascular waves.

\section{Methods}

\section{Model components}

This section describes the building blocks of the cardiovascular model. A summary of methods is provided where full details are available in previous publications. Model equations are provided in Table 1 and are numbered with a ' $T$ ' prefix.

\section{One-dimensional (1D) vascular modelling}

The non-linear 1D equations governing pressure, velocity and cross-sectional area in a single vessel segment (Eqs. T1,T2) were implemented as described previously, ${ }^{4,25}$ noting that we have assumed a flat velocity profile for the convective acceleration term and a profile with a boundary layer for the viscous friction term, as adopted by Alastruey et al; ${ }^{9}$ others have incorporated more detailed estimations of the velocity profile for this term, which are

particularly important for predictions of wall shear stress. ${ }^{29,30}$ For the viscoelastic pressurearea relation, a power law was used for the elastic term and a Voigt model for the viscous 
wall term (Eqs. T3,T4). ${ }^{25}$ Conservation of mass and continuity of total pressure were assumed at the junction of two or more $1 \mathrm{D}$ vessels, ${ }^{4,31}$ thus neglecting any junction-related pressure losses. The governing equations were solved with a finite element method, as described in Mynard et al. ${ }^{4}$ The viscoelastic term was neglected at junctions and on internal nodes was treated with the operator splitting technique described by Formaggia et $\mathrm{al}^{32}$ and Malossi et al. ${ }^{33}$

\section{Heart and valves}

For a detailed discussion of the heart model, see Mynard et al. ${ }^{34}$ Briefly, the four heart chambers were each represented as a time-varying elastance in series with a pressuredependent source resistance. ${ }^{25,35,36}$ Fig. $1 \mathrm{~A}$ shows a schematic of the left or right heart model, which incorporates an atrium with multiple inlet veins, an atrioventricular valve and a ventricle. Three forms of chamber interaction were accounted for, as depicted in Fig. 1. First, chamber elastances were subjected to an external (pericardial) pressure, modelled as an exponential function of pericardial cavity volume, which in turn is determined by instantaneous heart volume ${ }^{26}$ (Fig. 1B, Eq. T5); volume variations in any one chamber therefore affect the external pressure experienced by all chambers. Second, interactions between contralateral chambers via the atrioventricular septum are represented by Maughan et al's method ${ }^{37}$ (Fig. 1C, Eq. T6-T7). Third, descent of the atrioventricular (AV) plane contributes to atrial filling during ventricular contraction (Fig. 1D). This piston-like function formed the basis of a recently proposed alternative to the elastance heart model. ${ }^{38}$ In the current work, we took a different approach and incorporated the piston effect into the elastance model for the first time by assuming that AV plane descent decreases effective atrial elastance in proportion to AV velocity, and thereby aids atrial filling. AV 
velocity was assumed to follow the same waveform profile as the time rate of change of ventricular volume (i.e. ventricular flow, $q_{\mathrm{v}}$ ), ${ }^{38}$ with the last term in Eq. T6 accounting for this effect.

Heart valves were represented as in Mynard et $\mathrm{al}^{25}$ with the Bernoulli equation (Eqs. T12-T13) for the pressure-flow relation ${ }^{39}$ and dynamic valve motion considered to be a function of the instantaneous transvalvular pressure difference and valve position (Eqs. T14T15).

\section{Vascular beds}

Three types of vascular bed models were employed. The generic vascular bed model (Fig. $2 \mathrm{~A})$, used for all microvasculature beds except the liver and myocardium, is inspired by the three-element windkessel model and consists of 1 ) characteristic impedances that couple any number of connecting $1 \mathrm{D}$ arteries/veins to the lumped parameter microvasculature $\left.\left(Z_{\text {art }}, Z_{\text {ven }}\right), 2\right)$ lumped compliances on the arterial and venous side $\left(C_{\text {art }}, C_{\text {ven }}\right)$, and 3) a pressure-dependent vascular bed resistance $\left(R_{\mathrm{vb}}\right.$, Eq. T16). ${ }^{34,40,41}$

The liver has arterial and venous inlets. To account for the differing pressures of these inputs, arterial flow in the hepatic vascular bed model (Fig. 2B) passes through an extra compartment $\left(R_{\text {art }}, C_{\text {art }}\right.$ ) governing the vessels over which pressure drops to a common portal/arterial pressure in the liver lobules, whose compliance is designated $C_{\mathrm{p} / \mathrm{a}} \cdot{ }^{34}$ In all other respects, this model is the same as the generic vascular bed model.

Intramyocardial coronary vessels experience a large time-varying external pressure caused by the contracting heart muscle. This intramyocardial pressure $\left(p_{\mathrm{im}}\right)$ is greatest in the subendocardium and least in the subepicardium. ${ }^{42}$ The coronary vascular bed model (Fig. 2C) is identical to that in Mynard et $\mathrm{al}^{5}$ and consists of three myocardial layers 
(subendocardium, midwall, subepicardium), each containing two compliant compartments $\left(C_{1}, C_{2}\right)$. Three non-linear resistances $\left(R_{1}, R_{\mathrm{m}}, R_{2}\right)$ in each layer are dependent on blood volume in the two compartments via Eqs. T17-T19. ${ }^{5}$ The compliances are subjected to $p_{\mathrm{im}}$, calculated as the sum of cavity-induced extracellular pressure $\left(p_{\mathrm{CEP}}\right.$, pressure transmitted from the ventricular cavity through the wall) and shortening-induced intracellular pressure $\left(p_{\mathrm{SIP}}\right.$, pressure generated mechanically by the thickening heart muscle as it contracts). ${ }^{43} p_{\mathrm{SIP}}$ is assumed to be directly proportional to effective ventricular chamber elastance, that is,

$$
p_{\mathrm{SIP}}=\alpha_{\mathrm{SIP}}\left[p_{\mathrm{V}} /\left(v_{\mathrm{V}}-v_{p=0, \mathrm{~V}}\right)\right]
$$

where $\alpha_{\text {SIP }}$ is a constant and ' $V$ ' subscripts refer to the left ventricular cavity for the left ventricular free wall and septal myocardium, and the right ventricular cavity for the right ventricular free wall. The model is coupled to a terminal 1D artery and vein via penetrating artery/vein characteristic impedances and compliances $\left(Z_{\mathrm{pa}}, Z_{\mathrm{pv}}, C_{\mathrm{pa}}, C_{\mathrm{pv}}\right)$. For further details about the design, implementation and validation of the coronary model, see Mynard et al. ${ }^{5}$

\section{Model integration and parameterisation}

This section details how the model components were integrated on the basis of anatomical and functional data, along with approaches for parameter value selection. Where possible, parameters for the model were based on data from healthy, young adults (approximately 20-30 years of age, weight $75 \mathrm{~kg}$, height $175 \mathrm{~cm}$ ). Overall, the 1D networks contain 396 segments, 5359 nodes and 188 junctions in the 1D networks. The model was implemented in Matlab 2014a (The MathWorks, Inc., Natick, MA, USA). Each simulation was run until a steady state was achieved, defined as a change in peak pressure in all 1D segments of less 
than $1 \%$ between successive cardiac cycles ( 9 cycles required for the normal baseline simulation).

\section{D Vascular Networks}

The 1D vascular networks are shown in Fig. 3, with dimensions and connectivity data provided in Supplemental File 1. The systemic arterial network was adapted from previous studies, $^{2,4,6,7}$ with adjustments incorporated to ensure well-matched junctions in the forward direction. ${ }^{8}$ Unlike most previous models, in the present model multiple arteries can terminate in a common vascular bed (e.g. an 'arm' vascular bed rather than separate radial, ulnar and interosseus beds), which simplifies connection to the venous network, since there is not always a one-to-one anatomical relation between arteries and veins.

The systemic venous network was based on anatomical texts ${ }^{44-46}$ and other published data. Venous lengths were estimated from arterial lengths. Venous diameters were first estimated by assuming a vein-to-artery diameter ratio of 1.25 , where possible, and then adjusting values with the goal of achieving well-matching coupling in the backwards direction while keeping within the limits of available published data.

Dimensions of the main, left and right pulmonary arteries and four main pulmonary veins were derived from the literature. ${ }^{34,47-49}$ The remainder of the $1 \mathrm{D}$ pulmonary networks were generated using fractal relations as described by Qureshi et al, ${ }^{50}$

$$
D_{\mathrm{p}}^{\xi}=D_{\mathrm{d} 1}^{\xi}+D_{\mathrm{d} 2}^{\xi} \quad \text { and } \quad \gamma=\frac{r_{\mathrm{d} 2}^{2}}{r_{\mathrm{d} 1}^{2}}
$$

where the diameter $(D)$ of parent $(p)$ and daughter $(\mathrm{d} 1, \mathrm{~d} 2)$ vessels are related via the fractal exponent $\xi=2.76$ and asymmetry ratio $\gamma=0.43 .^{50,51}$ The resulting pulmonary arterial and 
venous networks contained the same number of segments and the same connectivity, in line with the known pairing of small pulmonary arteries and veins. A length/radius ratio of 2.55 was assumed for pulmonary arteries, ${ }^{52}$ along with matching lengths for corresponding veins. The 1D network was terminated after a parent radius of $5 \mathrm{~mm}$ was reached in both the artery and vein at a particular topological location, leading to 54 pulmonary arteries/veins being included. Small vessels between terminal artery/vein pairs were lumped into generic OD compartments (see Fig. 2A of the main manuscript).

The portal venous and epicardial coronary networks were based on published human data. ${ }^{44,45,53-57}$ Each instance of the coronary vascular bed model was supplied by a single artery and drained by a single vein. To estimate coronary venous dimensions, a veinto-artery diameter ratio of 1.4 was used for the terminal veins. ${ }^{58,59}$ Starting from the terminal veins, diameters of non-terminal coronary veins were found by repeated application of Eq. (2a), ${ }^{34}$ leading to a predicted coronary sinus diameter of $0.79 \mathrm{~cm}$, which compares well with the value of 0.81 measured in humans. ${ }^{60}$

Due to the paucity of available wave speed data throughout the vascular networks, reference wave speed $\left(c_{0}\right)$ for each 1D segment was set via the empirical formula suggested by Olufsen et al, ${ }^{61}$

$$
c_{0}^{2}=\frac{2}{3 \rho} \frac{E h}{D_{0}}=\frac{2}{3 \rho}\left[k_{1} \exp \left(k_{2} D_{0} / 2\right)+k_{3}\right]
$$

where $D_{0}$ is a reference diameter, $E$ is Young's modulus, $h$ is wall thickness, $\rho$ is blood density (assumed to be $1.06 \mathrm{~g} / \mathrm{cm}^{3}$ ). The empirical constants $k_{1}, k_{2}$ and $k_{3}$ were chosen to achieve normal wave speeds in the large vessels for a young adult human and a reasonable increase in smaller vessels (Table 2). 
Similar to Reymond et $\mathrm{al}^{1}{ }^{1}$ we estimated the following inverse linear dependence of the wall viscosity coefficient ( $\Gamma$ in Eq. T3) on systemic arterial diameter, based on published dynamic pressure-area relations in dogs and humans, ${ }^{62,63}$

$$
\Gamma=\frac{b_{1}}{D}+b_{0}
$$

where $b_{0}=400 \mathrm{~g} / \mathrm{s}$ and $b_{1}=100 \mathrm{~g} . \mathrm{cm} / \mathrm{s}$. Although these values are quite approximate, we found that halving $b_{1}$ led to no appreciable change in the resulting waveforms; on the other hand, when viscoelastic effects were excluded altogether, unrealisitic (albeit small) high frequency oscillations appeared in peripheral vessels. For the systemic veins and pulmonary vessels, we chose a constant value of $\Gamma=200 \mathrm{~g} / \mathrm{s}$, which led to a small amount of hysteresis in the pressure-area relation, in agreement with published animal data. ${ }^{64,65}$

Initial pressures in the 1D networks were equal to the reference pressures defining reference cross-sectional area $\left(A_{0}\right)$ and wave speed $\left(c_{0}\right)$, i.e. $80 / 5 \mathrm{mmHg}$ (systemic arterial/venous), 11/10 $\mathrm{mmHg}$ (pulmonary arterial/venous), and $8.5 \mathrm{mmHg}$ (portal venous). Initial velocity was zero in all segments.

\section{Microvascular Beds}

Vascular bed parameters are provided in Supplemental File 2. Resistances at reference transmural pressures $\left(p_{\mathrm{tm} 0}\right)$ are reported, with the latter determined as follows. Initial pressures in the 1D networks were used to calculate initial pressures across $C_{\text {art }}$ or $C_{\text {ven, }}$ by using standard 'DC voltage-division' (i.e. pressure division) equations across the resistors. Initial and instantaneous pressures across $C_{\text {art }}$ were then defined as $p_{\mathrm{tmo}}$ and $p_{\mathrm{tm}}$ respectively. Systemic vascular bed resistances were based on data in Stergiopulos et al, ${ }^{7}$ with values adapted to our model by combining and/or dividing amongst instances of the OD 
model where necessary. For example, 'radial', 'ulnar' and 'interosseus' resistances were combined into a single arm/shoulder resistance, which was then divided again into separate arm and shoulder resistances. Values were then adjusted to achieve a normal flow distribution as reported for humans ${ }^{66}$ and to achieve normal mean pressure and cardiac output. Hepatic resistances were estimated from published flow and pressure values. ${ }^{67}$

For the coronary model, resistances were volume-dependent, with Supplemental File 2 displaying reference resistances $\left(R_{0}\right)$ at reference volumes $\left(V_{0,1}\right.$ and $\left.V_{0,2}\right)$ of 2.5 and 8.0 $\mathrm{mL} / 100 \mathrm{~g}$ of myocardium (Eqs. T17-T19). ${ }^{5}$ Coronary resistances were determined iteratively in order to achieve the flow distribution reported by Fisher et al. ${ }^{68}$ As in Mynard et al, ${ }^{5}$ myocardial weights (and conductance, the inverse of resistance) were distributed among myocardial regions according to the inverse cube of $1 \mathrm{D}$ penetrating artery radii. Resistances were further distributed by assuming $R_{1}=1.2 R_{\mathrm{m}}$ and $R_{2}=0.5 R_{\mathrm{m}} .{ }^{5}$ The components of intramyocardial pressure $\left(p_{\mathrm{CEP}}\right.$ and $\left.p_{\mathrm{SIP}}\right)$ were determined as in Mynard et al, ${ }^{5}$ with $p_{\mathrm{CEP}}$ assumed to vary linearly across the heart wall from ventricular pressure on the endocardium to pericardial pressure on the epicardium (or from left to right ventricular pressure for the ventricular septum). Based on data in Rabbany et $\mathrm{al}^{69}$ the value of $\alpha_{\mathrm{SIP}}$ in Eq. (1) was $8.2 \mathrm{~mL}$, such that maximum $p_{\text {SIP }}$ was $20 \%$ of left ventricular cavity pressure.

The distribution of vascular compliance throughout the circulation is given in Table 5. These values were distributed amongst the respective $\mathrm{OD}$ vascular bed compartments according to the inverse of resistance, having first subtracted out the 1D network compliances. 


\section{Cardiac parameters}

Parameter values for the heart chambers and valves are given in Tables 3 and 4 , and were based on in vivo measurements, ${ }^{3,70-78}$ The input free-wall elastance waveform was a doubleHill function ${ }^{25,79}$ (Eq. T9-T11, Table 1). Initial chamber volumes are given in Table 3, while initial chamber pressures were calculated from these volumes and the prescribed elastance at end-diastole. The constant relating AV plane velocity to an effective right atrial elastance ( $\mu_{\mathrm{AV}}$ in Eq. T6) was estimated to achieve a normal peak systolic/diastolic velocity ratio of 1.6 in the superior vena cava, ${ }^{80}$ while left atrial $\mu_{\mathrm{Av}}$ was estimated as $2 / 3$ of the right atrial value based on mitral and tricuspid annulus displacement measurements. ${ }^{81}$ Constants governing the pericardial pressure-volume relation were $K_{\mathrm{pc}}=0.5 \mathrm{mmHg}, V_{0, \mathrm{pc}}=641 \mathrm{~mL}$ and $\Phi_{\mathrm{pc}}=40$, while pericardial cavity volume $\left(v_{\mathrm{pc}}\right)$ was calculated as the sum of instantaneous chamber volumes, pericardial fluid volume $\left(v_{\mathrm{pcf}}=30 \mathrm{~mL}\right)$ and myocardial volume $(192 \mathrm{~mL})$. These values resulted in a pericardial pressure of less than $0.5 \mathrm{mmHg}$ under normal conditions.

\section{Results}

\section{Comparisons with in vivo data}

Table 6 compares basic haemodynamic quantities from the model with published normal values for young adults. Fig. 4 compares model-derived pressure/flow waveforms with representative published in vivo waveforms from healthy adults. ${ }^{1,82-102}$ Importantly, the main waveform features, along with many smaller or more subtle features, are generally captured well by the model. Particularly noteworthy are 1) the evolution of the systemic arterial pressure and flow waveforms from proximal to distal vessels; ${ }^{1,97}$ 2) diastolic dominance of coronary arterial flow; ${ }^{93}$ 3) systolic dominance of coronary venous flow; ${ }^{84} 4$ ) 
systolic dominance of vena caval flow; ${ }^{80} 5$ ) diastolic dominance of pulmonary venous flow; ${ }^{103}$ and 6) low portal venous flow pulsatility. ${ }^{88,95}$

\section{Local Wave Intensity}

Model-generated pressure, velocity and wave intensity profiles at several key vascular locations are shown in Figs. 5 and 6, noting that wave intensity has been separated into forward and backward components. Waves with positive/negative wave intensity indicate waves propagating in/against the direction of mean blood flow, while compression/expansion waves are associated with an increase/decrease in pressure respectively. The haemodynamic effects and underlying mechanisms of the main waves are summarised in Table 7.

The aortic wave intensity profile is typical for humans ${ }^{14}$ and other species ${ }^{13,15}$, exhibiting a forward compression wave in early ejection $\left(\mathrm{FCW}_{\mathrm{ee}}\right)$, a forward expansion wave in late systole $\left(\mathrm{FEW}_{\mathrm{Is}}\right)$ and a small backward compression wave $(\mathrm{BCW})$ signifying vascular wave reflection of the $\mathrm{FCW}_{\text {ee. }}$ Carotid and brachial wave intensity profiles are similar to the aortic profile, except that the BCW is larger and a mid-systolic forward expansion (FEW $\mathrm{ms}_{\mathrm{s}}$ ) wave coincides with a fall in pressure and flow.

Wave intensity in the main pulmonary artery also contains the $\mathrm{FCW}_{\mathrm{ee}}$ and $\mathrm{FEW}_{\mathrm{Is}}$, but rather than a BCW, exhibits a backward expansion wave (BEW) in early-mid systole, caused by negative reflection of the $\mathrm{FCW}_{\mathrm{ee}}$. Nevertheless, a small $\mathrm{BCW}$ is present towards the end of systole, while negative reflection of the $\mathrm{FEW}_{\mathrm{ls}}$ leads to a $\mathrm{BCW}_{\mathrm{ls}}$ occurring around the time of valve closure.

Waves in the inferior vena cava (IVC) and pulmonary vein (PV) are qualitatively similar. Systolic flow acceleration is initiated by the aspirating effect of atrial relaxation (via 
$\mathrm{BEW}_{\mathrm{ar}}$ ) and is sustained by acceleration of $\mathrm{AV}$ plane descent $\left(B E W_{\mathrm{ada}}\right)$. In late systole, deceleration of $\mathrm{AV}$ plane descent reduces flow via a $\mathrm{BCW}_{\text {add }}$. Ventricular relaxation then draws blood into the atrium, leading to the diastolic flow peak $\left(B E W_{v d}\right)$, and finally, atrial contraction suppresses venous forward flow $\left(\mathrm{BCW}_{\mathrm{ac}}\right)$.

\section{Global Wave Intensity}

Fig. 7 plots overall peak forward and backward wave intensity (using a logarithmic scale) along six arterio-venous paths, i.e. from ventricle to atrium via the (A) brain, (B) right arm, (C) right leg, (D) abdomen/liver, (E) left ventricular myocardium and (F) right lung, recalling that the $\mathrm{FCW}_{\mathrm{ee}}$ and $\mathrm{BCW}_{\mathrm{ac}}$ are the largest waves in arteries and veins respectively. The $\mathrm{FCW}_{\mathrm{ee}}$ decreases in progressively more distal systemic arteries, although some wave amplification is predicted in the arm (Fig. 7B). Proximal arterial backward waves are approximately 1 to 1.5 orders of magnitude smaller than forward waves in all cases, increase in progressively distal conduit arteries, but then decrease again in peripheral arteries. Systemic venous wave intensity is several orders of magnitude smaller than arterial wave intensity and backward waves are larger than forward waves. Wave intensity is particularly low in portal veins (Fig. 7D). In the coronary circulation (Fig. 7E), backward wave intensity almost equals forward wave intensity in distal arteries, while in coronary veins, forward wave intensity is 1 to 2 orders of magnitude greater than that seen in other systemic veins. Pulmonary arterial wave intensity is approximately one order of magnitude smaller than systemic arterial wave intensity (Fig. 7F). Note that we have presented the spatial evolution of wave intensity; if this is divided by vessel cross-sectional area to produce a measure of wave energy, forward and backward waves decrease in progressively smaller vessels. 


\section{Interactions between cardiac function and vascular waves}

The influence of cardiac function on major vascular waves is shown in Table 8. Reducing chamber systolic or diastolic function, by decreasing maximal or increasing minimal freewall elastance by $50 \%$, reveals how alterations in the function of one chamber has substantial effects, not only on local waves, but also on 'remote' waves. For example, although depressed LV contractility most significantly affects aortic root $\mathrm{FCW}_{\text {ee }}$ and FEW (by $\sim 60 \%$ ), as would be expected, it also induces changes in pulmonary arterial, vena caval and pulmonary venous waves of between $4 \%$ and $38 \%$. Enlarging the right ventricle (by increasing RV $V_{0}$ by $150 \mathrm{~mL}$ ) increases pericardial constraint and reduces wave intensities in all locations by $9-44 \%$. Eliminating septal interactions $(\kappa=0)$ reveals an appreciable interdependence of vascular waves on pressure transmission from contralateral chambers (up to $25 \%$ ). Removing the effect of $A V$ plane motion on atrial elastance $(\mu=0)$ eliminates the corresponding $\mathrm{BEW}_{\mathrm{ada}}$ and $\mathrm{BEW}_{\text {add }}$ waves (see Table 7, data not shown in Table 8), causes a moderate reduction of venous $\mathrm{BCW}_{\mathrm{ac}}$ and $\mathrm{BEW}$ ar $(13-21 \%)$ and, aside from the MPA $\mathrm{FEW}_{\mathrm{Is}}(17 \%$ reduction), has a negligible effect $(<5 \%)$ on arterial waves.

\section{Discussion}

This paper described a comprehensive 1D model of the cardiovascular system. Modelgenerated haemodynamic waveforms reproduced characteristic features of published waveforms in all parts of the circulation with high fidelity, while predicted wave intensity profiles were closely representative of published in vivo data. The spatial evolution of wave intensity through all vascular networks was investigated for the first time, along with the dependence of vascular waves on key aspects of heart function and chamber mechanical interactions. 


\section{Novel aspects}

Previous 1D models have mainly focused on the systemic arterial tree, ${ }^{1,2,7,9}$ some with a high level of anatomical detail. ${ }^{10-12}$ Others have focused on limited vascular regions such as coronary arteries ${ }^{5}$ or the arm. ${ }^{104} \mathrm{~A}$ number of closed-loop models have combined a $1 \mathrm{D}$ systemic arterial network with OD models of systemic veins and the pulmonary circulation. ${ }^{105}$ Recently, closed-loop models incorporating 1D representations of the systemic arteries and veins have been presented, with a particular focus on cerebral venous haemodynamics, with simulated flow waveforms compared against MRI data. ${ }^{24,106}$ As far as we are aware, however, no single model has accounted for wave propagation effects, via anatomically realistic vascular networks, in all regions of the circulation including the large systemic/pulmonary arteries/veins, the coronary arteries/veins and portal veins. Our model therefore enabled comparisons of wave dynamics in all regions of the circulation, which would be near impossible to achieve in vivo.

The 1D networks were coupled to OD heart and microvascular bed models, allowing detailed study of ventriculo-vascular interactions. The windkessel-like vascular bed model has the benefit of enabling connection to an arbitrary and non-matching number of arteries and veins, while the pressure-dependent resistance accounts for an important system nonlinearity that is often neglected. Although not focused on in this paper, the detailed OD coronary model allows study of regional and transmural differences in blood flow dynamics, along with their dependence on heart function via intramyocardial pressure. ${ }^{5}$ We also introduced a simple OD model for representing the arterial and portal venous inputs to the liver. The heart model incorporated three forms of inter-chamber interaction, mediated via pericardial constraint (interaction between all chambers), ${ }^{26}$ the atrioventricular septum 
(left/right chamber interaction) ${ }^{37}$ and descent of the AV plane (atrioventricular interaction). The latter was introduced to the elastance model for the first time, on the basis that AV plane descent is a recognised contributor to atrial filling ${ }^{107-109}$ but has received little attention in modelling studies, except for the recent study of Maksuti et al. ${ }^{38}$

\section{Physiological insights}

Arterial wave intensity

A major strength of our modelling approach is its ability to add substantial new information to the limited available in vivo human data. Thus, although wave intensity has been measured in several locations in humans, only one study compared wave patterns in multiple locations (carotid, brachial and radial arteries). ${ }^{17}$ However, a direct comparison of central aortic and peripheral arterial wave patterns has not been performed. Our modelbased comparison of aortic, carotid and brachial arterial wave intensity revealed two noteworthy findings. The first was that the BCW was substantially smaller in the ascending aorta, compared with carotid and brachial sites (Fig. 5). This supports the notion that the arterial network is designed for optimal forward (but not backward) wave transmission. Second, a FEW ${ }_{\mathrm{ms}}$, designated the ' $\mathrm{X}$-wave' by Zambanini et $\mathrm{al}^{17}{ }^{17}$ was present in the carotid and brachial arteries but not the aorta. Although some have posited that this wave has a ventricular origin, ${ }^{110}$ our results show that this wave can exist in the absence of a corresponding aortic $\mathrm{FEW}_{\mathrm{ms}}$, hence supporting the alternative hypothesis that the peripheral $\mathrm{FEW}_{\mathrm{ms}}$ arises from negative re-reflection of the $\mathrm{BCW}$ due to impedance mismatching in the backward direction. ${ }^{17}$

In large pulmonary arteries, model data displayed a BEW that arises from negative reflection and augments systolic flow while reducing pressure; this contrasts with the flow 
decreasing $\mathrm{BCW}$ seen in systemic arteries. This wave has been observed in dogs and sheep, ${ }^{16,91}$ while in humans it has been reported in one conference abstract ${ }^{111}$ but was absent in two other preliminary reports. ${ }^{112,113}$ Hence, its prevalence, determinants and importance are largely unknown. In future studies, our modelling approach will complement in vivo studies by enabling investigation of how pulmonary arterial network properties influence pulmonary wave reflection.

Venous wave intensity

No studies of systemic venous wave intensity exist. The model-derived vena caval wave intensity presented in this paper is therefore novel, albeit primarily predictive. However, the main waves we identified are consistent with well-accepted concepts of venous haemodynamics. In particular, the venous flow waveform was determined almost entirely by atrial pressure fluctuations, that is, by backward waves. ${ }^{114}$ Systolic flow was related to the combined effects of atrial relaxation $\left(B E W_{a r}\right)$ and $A V$ plane descent $\left(B E W_{\text {ada }}\right)$, while the diastolic flow peak arose from ventricular relaxation $\left(B E W_{v d}\right)$. Systolic flow deceleration was related to deceleration of the descending atrioventricular plane towards the end of systole $\left(B E W_{\text {add }}\right)$, while late diastolic flow deceleration (known as the A-wave) was caused by atrial contraction via the $\mathrm{BCW}_{\mathrm{ac}}$.

Model-derived pulmonary venous wave dynamics were similar to the systemic side and were consistent with the two available human studies, ${ }^{115,116}$ with all waves predicted by our model being visible in the figures of these papers. However, our model data did not predict a secondary systolic flow peak (known as S2) that is sometimes seen in vivo. ${ }^{103,115,116}$ Unlike all other features of venous haemodynamics, this appears to be caused by a forward 
wave, which may arise from negative reflection in the pulmonary venous network ${ }^{116}$ or from transmission of the pulmonary arterial forward compression wave. ${ }^{115}$

\section{Global wave dynamics}

Substantial gaps exist in our knowledge of wave propagation and reflection in the circulation, in part because measurement of wave dynamics on a system-level is extremely difficult. A model-based assessment of the spatial evolution of wave intensity along major arterio-venous paths therefore led to several insights regarding global wave dynamics. First, the $\mathrm{FCW}_{\mathrm{ee}}$ in arteries and the $\mathrm{BCW}_{\mathrm{ac}}$ in veins decayed with increasing distance from the heart. This was mainly caused by dissipation of wave energy related to vessel wall viscosity, since eliminating wall viscosity (by setting $\Gamma=0$ in Eq. T3) not only eliminated the decrease, but led to a marked and steady increase of both $\mathrm{FCW}_{\mathrm{ee}}$ and $\mathrm{BCW}_{\mathrm{ac}}$ intensity (data not shown). Both this and an increasing $\mathrm{FCW}_{\mathrm{ee}}$ in the arm in Fig. 7 were caused by non-linear effects that amplify the forward compression wave as it propagates (note that non-linear effects attenuate expansion waves). ${ }^{18}$ Such amplification is caused by the pressuredependence of wave speed, along with convective acceleration and decreasing distensibility related to vessel tapering. ${ }^{117}$ Indeed, in additional simulations (not presented here), we found that brachial artery tapering was a major factor leading to wave intensity amplification in the arm; this may explain why such amplification was not found in other regions where the degree of tapering was lower. Whether compression waves grow or decay as they propagate is therefore determined by a balance of counteracting viscoelastic dissipation and non-linear amplification effects, highlighting the importance of accounting for both phenomena in 1D models. 
Second, the systemic arterial BCW increased in progressively distal conduit arteries. Although this may also be caused in part by wave dissipation, a wave-trapping phenomenon is likely to be partly responsible, whereby backward waves are re-reflected at vascular junctions. ${ }^{118,119} \mathrm{BCW}$ intensity then decreased again in the most peripheral arteries, which may suggest that this wave arises primarily from impedance mismatching related to arterial tapering, rather than mismatching at terminal vascular beds. However, this finding needs to be investigated in further detail.

Third, clear differences in wave intensity were evident in different vascular regions. Wave intensity magnitude was broadly correlated with the operating pressure of the respective vascular networks, being highest in systemic arteries, moderate in pulmonary arteries and lowest in veins. Wave intensity was extremely low in portal veins due to their relative isolation from the heart, with the compliant gastrointestinal vascular beds dissipating ventricular pulsations upstream and the hepatic vascular bed dissipating right atrial pulsations downstream. Conversely, the substantially larger backward/forward waves in coronary arteries/veins compared with other systemic arteries/veins are consistent with observations that intramyocardial pressure variations have a large effect on coronary haemodynamics. ${ }^{120}$

\section{Cardiac function, mechanical interactions and vascular waves}

This is the first study to investigate the effects of cardiac chamber function and interactions on vascular waves, a subject that again is difficult to investigate in vivo due to the need for simultaneous high fidelity measurements of cardiac function and vascular haemodynamics, along with the ability to manipulate chamber interactions. Importantly, we found that reducing systolic or diastolic function of any of the heart chambers not only had direct 
effects on 'local' vascular waves, but also indirect effects on 'remote' vascular waves (e.g. left ventricular function affected not only AoRt waves, but also MPA, IVC and RIPV waves, see Table 8). Indirect effects arise from two types of interaction. The first is in-series interaction, where, for example, a reduced LV $E_{f w}^{\max }$ decreases LV output, thereby decreasing venous return, $\mathrm{RV}$ preload and the $\mathrm{RV} F C W_{\text {ee. }}$. The second is related to chamber mechanical interactions. Feneley et $\mathrm{al}^{121}$ showed that LV pressure is partially transmitted across the ventricular septum into the RV. Our model data suggests that the resulting enhanced RV

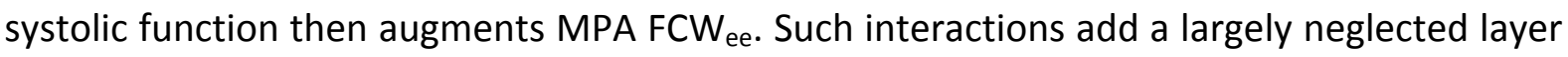
of complexity to the study of vascular waves and accounting for them may be particularly important in the study of cardiovascular diseases where 'local' pathology may have 'remote' haemodynamic consequences.

\section{Limitations and future development}

In this paper, only a preliminary analysis of wave dynamics throughout the circulation was possible and future work is needed to build upon these findings. We see the model as a relatively comprehensive framework that can be drawn upon and adapted for investigating a wide range of questions relating to cardiovascular physiology and disease. For example, global interactions are of prime importance in congenital heart disease, which now affects more adults than children. In addition, the model could be adapted to study the effects of aging and 'adult' cardiovascular diseases on wave dynamics. That this requires further consideration is indicated by the aortic root pressure waveform in Figure 4, which contained

some systolic pressure augmentation more typical of adults older than 30 years of age; ${ }^{122}$ the current model therefore does not perfectly represent a young adult. 
A number of phenomena were not represented in the model, such as gravity, oxygen transport and homeostatic regulation. We also did not incorporate venous valves or attempt to represent venous collapse dynamics; although unnecessary in the current paper (system venous flow was always positive), these would be needed to study gravitational and intrapleural pressure effects. The lumped vascular bed models were relatively simplistic and did not account for details of microvascular anatomy and flow; however, this approach is sufficient and convenient for studies of large vessel haemodynamics.

\section{Conclusion}

A comprehensive 1D model of the entire adult cardiovascular system has been presented, including a heart model that accounts for key inter-chamber interactions. We expect this model to be a highly useful resource for studying cardiovascular physiology and disease, particularly with respect to how complex interactions between the heart and vascular networks affect global wave dynamics.

\section{Acknowledgments}

J. P. Mynard acknowledges the support of a CJ Martin Early Career Fellowship from the National Health and Medical Research Council of Australia. This work was supported in part by the Victorian Government's Operational Infrastructure Support Program.

\section{Conflicts of Interest: None}

\section{References}

1. Reymond, P., F. Merenda, F. Perren, D. Rufenacht and N. Stergiopulos. Validation of a one-dimensional model of the systemic arterial tree. Am. J. Physiol. Heart Circ. Physiol. 297:H208-222, 2009. 
2. Avolio, A. Multi-branched model of the human arterial system. Med. Biol. Eng. Comput. 18:709-718, 1980.

3. Liang, F., S. Takagi, R. Himeno and H. Liu. Multi-scale modeling of the human cardiovascular system with applications to aortic valvular and arterial stenoses. Med. Biol. Eng. Comput. 47:743-755, 2009.

4. Mynard, J. P. and P. Nithiarasu. A 1D arterial blood flow model incorporating ventricular pressure, aortic valve and regional coronary flow using the locally conservative Galerkin (LCG) method. Comm. Numer. Methods Eng. 24:367-417, 2008.

5. Mynard, J. P., D. J. Penny and J. J. Smolich. Scalability and in vivo validation of a multiscale numerical model of the left coronary circulation. Am. J. Physiol. Heart Circ. Physiol. 306:H517-H528, 2014.

6. Westerhof, N., F. Bosman, C. J. De Vries and A. Noordergraaf. Analog studies of the human systemic arterial tree. J. Biomech. 2:121-134, 1969.

7. Stergiopulos, N., D. F. Young and T. R. Rogge. Computer simulation of arterial flow with applications to arterial and aortic stenoses. J. Biomech. 25:1477-1488, 1992.

8. Wang, J. J. and K. H. Parker. Wave propagation in a model of the arterial circulation. J. Biomech. 37:457-470, 2004.

9. Alastruey, J., A. W. Khir, K. S. Matthys, P. Segers, S. J. Sherwin, P. R. Verdonck, K. H. Parker and J. Peiró. Pulse wave propagation in a model human arterial network: Assessment of 1-D visco-elastic simulations against in vitro measurements. J. Biomech. 44:2250-2258, 2011.

10. Blanco, P. J., S. M. Watanabe, E. A. Dari, M. A. R. Passos and R. A. Feijóo. Blood flow distribution in an anatomically detailed arterial network model: Criteria and algorithms. Biomech. Model. Mechanobiol. 13:1303-1330, 2014.

11. Blanco, P. J., S. M. Watanabe and R. A. Feijoo. Identification of vascular territory resistances in one-dimensional hemodynamics simulations. J. Biomech. 45:2066-2073, 2012. 12. Blanco, P., S. Watanabe, M. Passos, P. Lemos and R. Feijoo. An anatomically detailed arterial network model for one-dimensional computational hemodynamics. IEEE Trans. Biomed. Eng. 62:736-753, 2014. 
13. Penny, D. J., J. P. Mynard and J. J. Smolich. Aortic wave intensity analysis of ventricularvascular interaction during incremental dobutamine infusion in adult sheep. Am. J. Physiol. Heart Circ. Physiol. 294:H481-489, 2008.

14. Biglino, G., J. A. Steeden, C. Baker, S. Schievano, A. M. Taylor, K. H. Parker and V. Muthurangu. A non-invasive clinical application of wave intensity analysis based on ultrahigh temporal resolution phase-contrast cardiovascular magnetic resonance. J. Cardiovasc. Magn. Reson. 14:1186, 2012.

15. Jones, C. J., M. Sugawara, Y. Kondoh, K. Uchida and K. H. Parker. Compression and expansion wavefront travel in canine ascending aortic flow: Wave intensity analysis. Heart Vessels 16:91-98, 2002.

16. Dwyer, N., A. Yong and D. Kilpatrick. Variable open-end wave reflection in the pulmonary arteries of anesthetized sheep. J. Physiol. Sci. 62:21-28, 2012.

17. Zambanini, A., S. L. Cunningham, K. H. Parker, A. W. Khir, G. T. S. A. Mc and A. D. Hughes. Wave-energy patterns in carotid, brachial, and radial arteries: A noninvasive approach using wave-intensity analysis. Am. J. Physiol. Heart Circ. Physiol. 289:H270-H276, 2005.

18. Mynard, J., D. J. Penny and J. J. Smolich. Wave intensity amplification and attenuation in non-linear flow: Implications for the calculation of local reflection coefficients. J. Biomech. 41:3314-3321, 2008.

19. Parker, K. H. An introduction to wave intensity analysis. Med. Biol. Eng. Comput. 47:175188, 2009.

20. Mynard, J. P. and J. J. Smolich. Wave potential and the one-dimensional windkessel as a wave-based paradigm of diastolic arterial hemodynamics. Am. J. Physiol. Heart Circ. Physiol. 307:H307-H318, 2014.

21. Willemet, M. and J. Alastruey. Arterial pressure and flow wave analysis using timedomain 1-D hemodynamics. Ann. Biomed. Eng. 43:190-206, 2014.

22. Alastruey, J., A. A. E. Hunt and P. D. Weinberg. Novel wave intensity analysis of arterial pulse wave propagation accounting for peripheral reflections. Int. J. Numer. Methods Biomed. Eng. 30:249-279, 2014. 
23. Blanco, P. and R. Feijóo. A dimensionally-heterogeneous closed-loop model for the cardiovascular system and its applications. Med. Eng. Phys. 35:652-667, 2013.

24. Müller, L. O. and E. F. Toro. Enhanced global mathematical model for studying cerebral venous blood flow. J. Biomech. 47:3361-3372, 2014.

25. Mynard, J. P., M. R. Davidson, D. J. Penny and J. J. Smolich. A simple, versatile valve model for use in lumped parameter and one-dimensional cardiovascular models. Int. J. Numer. Methods Biomed. Eng. 28:626-641, 2012.

26. Sun, Y., M. Beshara, R. J. Lucariello and S. A. Chiaramida. A comprehensive model for right-left heart interaction under the influence of pericardium and baroreflex. Am. J. Physiol. Heart Circ. Physiol. 272:H1499-1515, 1997.

27. Lumens, J., T. Delhaas, B. Kirn and T. Arts. Three-wall segment (TriSeg) model describing mechanics and hemodynamics of ventricular interaction. Ann. Biomed. Eng. 37:2234-2255, 2009.

28. Luo, C., D. Ware, J. Zwischenberger and J. Clark. Using a human cardiopulmonary model to study and predict normal and diseased ventricular mechanics, septal interaction, and atrio-ventricular blood flow patterns. Cardiovasc. Eng. 7:17-31, 2007.

29. Bessems, D., M. Rutten and F. N. Van de Vosse. A wave propagation model of blood flow in large vessels using an approximate velocity profile function. J. Fluid Mech. 580:145-168, 2007.

30. van de Vosse, F. N. and N. Stergiopulos. Pulse wave propagation in the arterial tree. Ann. Rev. Fluid Mech. 43:467-499, 2011.

31. Sherwin, S. J., V. Franke, J. Peiró and K. Parker. One-dimensional modelling of a vascular network in space-time variables. J. Eng. Math. 47:217-250, 2003.

32. Formaggia, L., D. Lamponi and A. Quarteroni. One-dimensional models for blood flow in arteries. J. Eng. Math. 47:251-276, 2003.

33. Malossi, A. C. I., P. J. Blanco and S. Deparis. A two-level time step technique for the partitioned solution of one-dimensional arterial networks. Comput. Meth. Appl. Mech. Eng. 237-240:212-226, 2012. 
34. Mynard, J. P. Computer modelling and wave intensity analysis of perinatal cardiovascular function and dysfunction PhD thesis, Department of Paediatrics, University of Melbourne 2011.

35. Shroff, S. G., J. S. Janicki and K. T. Weber. Evidence and quantitation of left ventricular systolic resistance. Am. J. Physiol. Heart Circ. Physiol. 249:H358-370, 1985.

36. Little, W. C. and G. L. Freeman. Description of LV pressure-volume relations by timevarying elastance and source resistance. Am. J. Physiol. Heart Circ. Physiol. 253:H83-90, 1987.

37. Maughan, W. L., K. Sunagawa and K. Sagawa. Ventricular systolic interdependence: Volume elastance model in isolated canine hearts. Am. J. Physiol. Heart Circ. Physiol. 253:H1381-1390, 1987.

38. Maksuti, E., A. Bjällmark and M. Broomé. Modelling the heart with the atrioventricular plane as a piston unit. Med. Eng. Phys. 37:87-92, 2015.

39. Sun, Y., B. J. Sjoberg, P. Ask, D. Loyd and B. Wranne. Mathematical model that characterizes transmitral and pulmonary venous flow velocity patterns. Am. J. Physiol. Heart Circ. Physiol. 268:H476-489, 1995.

40. Shoukas, A. A. Pressure-flow and pressure-volume relations in the entire pulmonary vascular bed of the dog determined by two-port analysis. Circ. Res. 37:809-818, 1975.

41. Magder, S. Starling resistor versus compliance. Which explains the zero-flow pressure of a dynamic arterial pressure-flow relation? Circ. Res. 67:209-220, 1990.

42. Heineman, F. W. and J. Grayson. Transmural distribution of intramyocardial pressure measured by micropipette technique. Am. J. Physiol. Heart Circ. Physiol. 249:H1216-1223, 1985.

43. Algranati, D., G. S. Kassab and Y. Lanir. Mechanisms of myocardium-coronary vessel interaction. Am. J. Physiol. Heart Circ. Physiol. 298:H861-873, 2010.

44. Martini, F. H. Fundamentals of anatomy \& physiology. 4th edn, New Jersey: Prentice Hall International, 1998.

45. Gray, H. Anatomy of the human body. 20th edn, Philadephia: Lea \& Felbiger, 1918. 
46. Nowinski, W. L., A. Thirunavuukarasuu, I. Volkau, Y. Marchenko and V. M. Runge. The cerefy atlas of cerebral vasculature. Thieme New York, 2009.

47. Kim, Y.-H., E. M. Marom, J. E. Herndon and H. P. McAdams. Pulmonary vein diameter, cross-sectional area, and shape: CT analysis. Radiology 235:43-49, 2005.

48. Wittkampf, F. H. M., E.-J. Vonken, R. Derksen, P. Loh, B. Velthuis, E. F. D. Wever, L. V. A. Boersma, B. J. Rensing and M.-J. Cramer. Pulmonary vein ostium geometry: Analysis by magnetic resonance angiography. Circulation 107:21-23, 2003.

49. Edwards, P. D., R. K. Bull and R. Coulden. CT measurement of main pulmonary artery diameter. Brit. J. Radiol. 71:1018-1020, 1998.

50. Qureshi, M. U., G. A. Vaughan, C. Sainsbury, M. Johnson, C. Peskin, M. Olufsen and N. A. Hill. Numerical simulation of blood flow and pressure drop in the pulmonary arterial and venous circulation. Biomech. Model. Mechanobiol. 13:1137-1154, 2014.

51. Glenny, R. W. and H. T. Robertson. Fractal modeling of pulmonary blood flow heterogeneity. J. Appl. Physiol. 70:1024-1030, 1991.

52. Huang, W., R. T. Yen, M. McLaurine and G. Bledsoe. Morphometry of the human pulmonary vasculature. J. Appl. Physiol. 81:2123-2133, 1996.

53. Schmassmann, A., M. Zuber, M. Livers, K. Jager, H. R. Jenzer and H. F. Fehr. Recurrent bleeding after variceal hemorrhage: Predictive value of portal venous duplex sonography. Am. J. Roentgenol. 160:41-47, 1993.

54. Keats, T. E. and C. Sistrom. Atlas of radiologic measurement. Missouri, USA: Mosby, Inc., 2001.

55. Xu, R. Y., B. Liu and N. Lin. Therapeutic effects of endoscopic variceal ligation combined with partial splenic embolization for portal hypertension. World J. Gastroenterol. 10:10721074, 2004.

56. Unsal, N. H., A. Erden and I. Erden. Evaluation of the splenic vein diameter and longitudinal size of the spleen in patients with gamna-gandy bodies. Diagn. Interv. Radiol. 12:125-128, 2006. 
57. Dodge, J. T. J., B. G. Brown, E. L. Bolson and H. T. Dodge. Lumen diameter of normal human coronary arteries. Influence of age, sex, anatomic variation, and left ventricular hypertrophy or dilation. Circulation 86:232-246, 1992.

58. Kassab, G. S., D. H. Lin and Y. C. Fung. Morphometry of pig coronary venous system. Am. J. Physiol. Heart Circ. Physiol. 267:H2100-2113, 1994.

59. Kassab, G. S., C. A. Rider, N. J. Tang and Y. C. Fung. Morphometry of pig coronary arterial trees. Am. J. Physiol. Heart Circ. Physiol. 265:H350-365, 1993.

60. Gunes, Y., U. Guntekin, M. Tuncer, Y. Kaya and A. Akyol. Association of coronary sinus diameter with pulmonary hypertension. Echocardiography 25:935-940, 2008.

61. Olufsen, M. S. Structured tree outflow condition for blood flow in larger systemic arteries. Am. J. Physiol. Heart Circ. Physiol. 276:H257-268, 1999.

62. Bergel, D. H. The dynamic elastic properties of the arterial wall. J. Physiol. 156:458-469, 1961.

63. Learoyd, B. M. and M. G. Taylor. Alterations with age in the viscoelastic properties of human arterial walls. Circ. Res. 18:278-292, 1966.

64. Gusic, R. J., M. Petko, R. Myung, J. William Gaynor and K. J. Gooch. Mechanical properties of native and ex vivo remodeled porcine saphenous veins. J. Biomech. 38:17701779, 2005.

65. Patel, D. J., D. P. Schilder and A. J. Mallos. Mechanical properties and dimensions of the major pulmonary arteries. J. Appl. Physiol. 15:92-96, 1960.

66. Lantz, B., J. Foerster, D. Link and J. Holcroft. Regional distribution of cardiac output: Normal values in man determined by video dilution technique. Am. J. Roentgenol. 137:903907, 1981.

67. Guyton, A. C. and J. E. Hall. Textbook of medical physiology. 9th edn, Pennsylvania: W.B. Saunders Company, 1996.

68. Fisher, D. J., M. A. Heymann and A. M. Rudolph. Regional myocardial blood flow and oxygen delivery in fetal, newborn, and adult sheep. Am. J. Physiol. Heart Circ. Physiol. 243:H729-731, 1982. 
69. Rabbany, S. Y., J. Y. Kresh and A. Noordergraaf. Intramyocardial pressure: Interaction of myocardial fluid pressure and fiber stress. Am. J. Physiol. Heart Circ. Physiol. 257:H357-364, 1989.

70. Kass, D. A., M. Midei, W. Graves, J. A. Brinker and W. L. Maughan. Use of a conductance (volume) catheter and transient inferior vena caval occlusion for rapid determination of pressure-volume relationships in man. Cathet. Cardiovasc. Diagn. 15:192-202, 1988.

71. Takeuchi, M., M. Odake, H. Takaoka, Y. Hayashi and M. Yokoyama. Comparison between preload recruitable stroke work and the end-systolic pressure-volume relationship in man. Eur. Heart J. 13:80-84, 1992.

72. Brown, K. A. and R. V. Ditchey. Human right ventricular end-systolic pressure-volume relation defined by maximal elastance. Circulation 78:81-91, 1988.

73. Maniar, H. S., S. M. Prasad, S. L. Gaynor, C. M. Chu, P. Steendijk and M. R. Moon. Impact of pericardial restraint on right atrial mechanics during acute right ventricular pressure load. Am. J. Physiol. Heart Circ. Physiol. 284:H350-357, 2003.

74. Yellin, E. L., S. Nikolic and R. W. Frater. Left ventricular filling dynamics and diastolic function. Prog. Cardiovasc. Dis. 32:247-271, 1990.

75. Courtois, M., B. Barzilai, F. Gutierrez and P. A. Ludbrook. Characterization of regional diastolic pressure gradients in the right ventricle. Circulation 82:1413-1423, 1990.

76. Pettersen, M. D., W. Du, M. E. Skeens and R. A. Humes. Regression equations for calculation of z scores of cardiac structures in a large cohort of healthy infants, children, and adolescents: An echocardiographic study. J. Am. Soc. Echocardiogr. 21:922-934, 2008.

77. Leyh, R. G., C. Schmidtke, H.-H. Sievers and M. H. Yacoub. Opening and closing characteristics of the aortic valve after different types of valve-preserving surgery. Circulation 100:2153-2160, 1999.

78. Saito, S., Y. Araki, A. Usui, T. Akita, H. Oshima, J. Yokote and Y. Ueda. Mitral valve motion assessed by high-speed video camera in isolated swine heart. Eur. J. Cardiothorac. Surg. 30:584-591, 2006. 
79. Stergiopulos, N., J. J. Meister and N. Westerhof. Determinants of stroke volume and systolic and diastolic aortic pressure. Am. J. Physiol. Heart Circ. Physiol. 270:H2050-2059, 1996.

80. Appleton, C. P., L. K. Hatle and R. L. Popp. Superior vena cava and hepatic vein doppler echocardiography in healthy adults. J. Am. Coll. Cardiol. 10:1032-1039, 1987.

81. Maffessanti, F., P. Gripari, G. Pontone, D. Andreini, E. Bertella, S. Mushtaq, G. Tamborini, L. Fusini, M. Pepi and E. G. Caiani. Three-dimensional dynamic assessment of tricuspid and mitral annuli using cardiovascular magnetic resonance. Eur. Heart J. Cardiovasc. Imaging 14:986-995, 2013.

82. Braunwald, E., A. P. Fishman and A. Cournand. Time relationship of dynamic events in the cardiac chambers, pulmonary artery and aorta in man. Circ. Res. 4:100-107, 1956.

83. Cohen, M. L., B. S. Cohen, I. Kronzon, G. W. Lighty and H. E. Winer. Superior vena caval blood flow velocities in adults: A doppler echocardiographic study. J. Appl. Physiol. 61:215219, 1986.

84. Watzinger, N., G. K. Lund, M. Saeed, G. P. Reddy, P. A. Araoz, M. Yang, A. B. Schwartz, M. Bedigian and C. B. Higgins. Myocardial blood flow in patients with dilated cardiomyopathy: Quantitative assessment with velocity-encoded cine magnetic resonance imaging of the coronary sinus. J. Magn. Reson. Imaging 21:347-353, 2005.

85. Mohiaddin, R. H., S. L. Wann, R. Underwood, D. N. Firmin, S. Rees and D. B. Longmore. Vena caval flow: Assessment with cine MR velocity mapping. Radiology 177:537-541, 1990.

86. Wexler, L., D. H. Bergel, I. T. Gabe, G. S. Makin and C. J. Mills. Velocity of blood flow in normal human venae cavae. Circ. Res. 23:349-359, 1968.

87. Mostbeck, G. H. Duplex and color doppler imaging of the venous system. Springer, 2004.

88. Barakat, M. Non-pulsatile hepatic and portal vein waveforms in patients with liver cirrhosis: Concordant and discordant relationships. Brit. J. Radiol. 77:547-550, 2004.

89. Bowman, A. W. and S. J. Kovács. Prediction and assessment of the time-varying effective pulmonary vein area via cardiac MRI and doppler echocardiography. Am. J. Physiol. Heart Circ. Physiol. 288:H280-H286, 2005. 
90. Greenfield, J. C. J. R. and D. M. J. R. Griggs. Relation between pressure and diameter in main pulmonary artery of man. J. Appl. Physiol. 18:557-559, 1963.

91. Hollander, E. H., J. J. Wang, G. M. Dobson, K. H. Parker and J. V. Tyberg. Negative wave reflections in pulmonary arteries. Am. J. Physiol. Heart Circ. Physiol. 281:H895-902, 2001.

92. Wilson, N., S. J. Goldberg, D. F. Dickinson and O. Scott. Normal intracardiac and great artery blood velocity measurements by pulsed doppler echocardiography. Br. Heart J. 53:451-458, 1985.

93. Gao, Z., T. E. Wilson, R. C. Drew, J. Ettinger and K. D. Monahan. Altered coronary vascular control during cold stress in healthy older adults. Am. J. Physiol. Heart Circ. Physiol. 302:H312-H318, 2012.

94. Schreiber, S. J., E. Stolz and J. M. Valdueza. Transcranial ultrasonography of cerebral veins and sinuses. Eur. J. Ultrasound 16:59-72, 2002.

95. Gorg, C., J. Riera-Knorrenschild and J. Dietrich. Colour doppler ultrasound flow patterns in the portal venous system. Brit. J. Radiol. 75:919-929, 2002.

96. Gardin, J. M., C. S. Burn, W. J. Childs and W. L. Henry. Evaluation of blood flow velocity in the ascending aorta and main pulmonary artery of normal subjects by doppler echocardiography. Am. Heart J. 107:310-319, 1984.

97. Kroeker, E. J. and E. H. Wood. Comparison of simultaneously recorded central and peripheral arterial pressure pulses during rest, exercise and tilted position in man. Circ. Res. 3:623-632, 1955.

98. Graettinger, W. F., E. R. Greene and W. F. Voyles. Doppler predictions of pulmonary artery pressure, flow, and resistance in adults. Am. Heart J. 113:1426-1436, 1987.

99. Gwilliam, M. N., N. Hoggard, D. Capener, P. Singh, A. Marzo, P. K. Verma and I. D. Wilkinson. MR derived volumetric flow rate waveforms at locations within the common carotid, internal carotid, and basilar arteries. J. Cereb. Blood Flow Metab. 29:1975-1982, 2009.

100. Ford, M. D., N. Alperin, S. H. Lee, D. W. Holdsworth and D. A. Steinman. Characterization of volumetric flow rate waveforms in the normal internal carotid and vertebral arteries. Physiol. Meas. 26:477-488, 2005. 
101. Greve, J. M., A. S. Les, B. T. Tang, M. T. Draney Blomme, N. M. Wilson, R. L. Dalman, N. J. Pelc and C. A. Taylor. Allometric scaling of wall shear stress from mice to humans: Quantification using cine phase-contrast MRI and computational fluid dynamics. Am. J. Physiol. Heart Circ. Physiol. 291:H1700-H1708, 2006.

102. Boonyasirinant, T., P. Rajiah, R. M. Setser, M. L. Lieber, H. M. Lever, M. Y. Desai and S. D. Flamm. Aortic stiffness is increased in hypertrophic cardiomyopathy with myocardial fibrosis: Novel insights in vascular function from magnetic resonance imaging. J. Am. Coll. Cardiol. 54:255-262, 2009.

103. de Marchi, S. F., M. Bodenmüller, D. L. Lai and C. Seiler. Pulmonary venous flow velocity patterns in 404 individuals without cardiovascular disease. Heart 85:23-29, 2001.

104. Huberts, W., A. S. Bode, W. Kroon, R. N. Planken, J. H. M. Tordoir, F. N. van de Vosse and E. M. H. Bosboom. A pulse wave propagation model to support decision-making in vascular access planning in the clinic. Med. Eng. Phys. 34:233-248, 2012.

105. Liang, F. Y., S. Takagi, R. Himeno and H. Liu. Biomechanical characterization of ventricular-arterial coupling during aging: A multi-scale model study. J. Biomech. 42:692704, 2009.

106. Müller, L. O. and E. F. Toro. A global multiscale mathematical model for the human circulation with emphasis on the venous system. Int. J. Numer. Methods Biomed. Eng. 30:681-725, 2014.

107. Steding-Ehrenborg, K., M. Carlsson, S. Stephensen and H. Arheden. Atrial aspiration from pulmonary and caval veins is caused by ventricular contraction and secures $70 \%$ of the total stroke volume independent of resting heart rate and heart size. Clin. Physiol. Funct. Imaging 33:233-240, 2013.

108. Tsakiris, A. G., D. A. Gordon, R. Padiyar, D. Fréchette and C. Labrosse. The role of displacement of the mitral annulus in left atrial filling and emptying in the intact dog. Can. J. Physiol. Pharmacol. 56:447-457, 1978.

109. Keren, G., E. H. Sonnenblick and T. H. LeJemtel. Mitral anulus motion. Relation to pulmonary venous and transmitral flows in normal subjects and in patients with dilated cardiomyopathy. Circulation 78:621-629, 1988. 
110. Niki, K., M. Sugawara, D. Chang, A. Harada, T. Okada and R. Tanaka. Effects of sublingual nitroglycerin on working conditions of the heart and arterial system: Analysis using wave intensity. J. Med. Ultrason. 32:145-152, 2005.

111. Quail, M. A., D. S. Knight, J. A. Steeden, A. Taylor and V. Muthurangu. Novel magnetic resonance wave intensity analysis in pulmonary hypertension. J. Cardiovasc. Magn. Reson. 16:P252, 2014.

112. Su, J., C. Manisty, K. Parker and A. Hughes. Wave intensity analysis in the pulmonary artery. Artery Res. 8:127, 2014.

113. Lau, E. M. T., D. Abelson, N. Dwyer, Y. Yu, M. K. Ng and D. S. Celermajer. Assessment of ventriculo-arterial interaction in pulmonary arterial hypertension using wave intensity analysis. Eur. Respir. J. 43:1804-1807, 2014.

114. Brawley, R., H. Oldham, J. Vasko, R. Henney and A. Morrow. Influence of right atrial pressure pulse on instantaneous vena caval blood flow. Am. J. Physiol. 211:347-353, 1966.

115. Smiseth, O. A., C. R. Thompson, K. Lohavanichbutr, H. Ling, J. G. Abel, R. T. Miyagishima, S. V. Lichtenstein and J. Bowering. The pulmonary venous systolic flow pulse--its origin and relationship to left atrial pressure. J. Am. Coll. Cardiol. 34:802-809, 1999.

116. Hellevik, L., P. Segers, N. Stergiopulos, F. Irgens, P. Verdonck, C. Thompson, K. Lo, R. Miyagishima and $\mathrm{O}$. Smiseth. Mechanism of pulmonary venous pressure and flow waves. Heart Vessels 14:67-71, 1999.

117. Anliker, M., R. L. Rockwell and E. Ogden. Nonlinear analysis of flow pulses and shock waves in arteries, Part I: Derivation and properties of mathematical model. Zeitschrift fur Angewandte Mathematik und Physik (ZAMP) 22:217-246, 1971.

118. Davies, J. E., J. Alastruey, D. P. Francis, N. Hadjiloizou, Z. I. Whinnett, C. H. Manisty, J. Aguado-Sierra, K. Willson, R. A. Foale, I. S. Malik, A. D. Hughes, K. H. Parker and J. Mayet. Attenuation of wave reflection by wave entrapment creates a "horizon effect" in the human aorta. Hypertension 60:778-785, 2012.

119. Trachet, B., P. Reymond, J. Kips, A. Swillens, M. De Buyzere, B. Suys, N. Stergiopulos and P. Segers. Numerical validation of a new method to assess aortic pulse wave velocity 
from a single recording of a brachial artery waveform with an occluding cuff. Ann. Biomed. Eng. 38:876-888, 2010.

120. Davies, J. E., Z. I. Whinnett, D. P. Francis, C. H. Manisty, J. Aguado-Sierra, K. Willson, R. A. Foale, I. S. Malik, A. D. Hughes, K. H. Parker and J. Mayet. Evidence of a dominant backward-propagating "suction" wave responsible for diastolic coronary filling in humans, attenuated in left ventricular hypertrophy. Circulation 113:1768-1778, 2006.

121. Feneley, M. P., T. P. Gavaghan, D. W. Baron, J. A. Branson, P. R. Roy and J. J. Morgan. Contribution of left ventricular contraction to the generation of right ventricular systolic pressure in the human heart. Circulation 71:473-480, 1985.

122. Murgo, J. P., N. Westerhof, J. P. Giolma and S. A. Altobelli. Aortic input impedance in normal man: Relationship to pressure wave forms. Circulation 62:105-116, 1980.

123. Smith, N. P., A. J. Pullan and P. J. Hunter. An anatomically based model of transient coronary blood flow in the heart. SIAM J. Appl. Math. 62:990-1018, 2002.

124. Wiesmann, F., S. E. Petersen, P. M. Leeson, J. M. Francis, M. D. Robson, Q. Wang, R. Choudhury, K. M. Channon and S. Neubauer. Global impairment of brachial, carotid, and aortic vascular function in young smokers: Direct quantification by high-resolution magnetic resonance imaging. J. Am. Coll. Cardiol. 44:2056-2064, 2004.

125. Gozna, E. R., A. E. Marble, A. Shaw and J. G. Holland. Age-related changes in the mechanics of the aorta and pulmonary artery of man. J. Appl. Physiol. 36:407-411, 1974.

126. Nippa, J. H., R. H. Alexander and R. Folse. Pulse wave velocity in human veins. J. Appl. Physiol. 30:558-563, 1971.

127. Arts, T., R. T. Kruger, W. van Gerven, J. A. Lambregts and R. S. Reneman. Propagation velocity and reflection of pressure waves in the canine coronary artery. Am. J. Physiol. Heart Circ. Physiol. 237:H469-474, 1979.

128. Echt, M., J. Düweling, O. H. Gauer and L. Lange. Effective compliance of the total vascular bed and the intrathoracic compartment derived from changes in central venous pressure induced by volume changes in man. Circ. Res. 34:61-68, 1974.

129. Alfie, J., G. D. Waisman, C. R. Galarza and M. I. Camera. Contribution of stroke volume to the change in pulse pressure pattern with age. Hypertension 34:808-812, 1999. 
130. Takatsu, H., K. Gotoh, T. Suzuki, Y. Ohsumi, Y. Yagi, T. Tsukamoto, Y. Terashima, K. Nagashima and S. Hirakawa. Quantitative estimation of compliance of human systemic veins by occlusion plethysmography with radionuclide--methodology and the effect of nitroglycerin. Jpn. Circ. J. 53:245-254, 1989.

131. Milnor, W. R. Hemodynamics. 2nd edn, Baltimore: Williams \& Wilkins, 1989.

132. Tanaka, T., M. Arakawa, T. Suzuki, M. Gotoh, H. Miyamoto and S. Hirakawa. Compliance of human pulmonary "venous" system estimated from pulmonary artery wedge pressure tracings--comparison with pulmonary arterial compliance. Jpn. Circ. J. 50:127-139, 1986.

133. Hudsmith, L. E., S. E. Petersen, J. M. Francis, M. D. Robson and S. Neubauer. Normal human left and right ventricular and left atrial dimensions using steady state free precession magnetic resonance imaging. J. Cardiovasc. Magn. Reson. 7:775-782, 2005.

134. Sievers, B., M. Addo, F. Breuckmann, J. Barkhausen and R. Erbel. Reference right atrial function determined by steady-state free precession cardiovascular magnetic resonance. J. Cardiovasc. Magn. Reson. 9:807-814, 2007.

135. Krook, H. Estimation of portal venous pressure by occlusive hepatic vein catheterization. Scand. J. Clin. Lab. Invest. 5:285-292, 1953.

136. Iwase, M., K. Nagata, H. Izawa, M. Yokota, S. Kamihara, H. Inagaki and H. Saito. Agerelated changes in left and right ventricular filling velocity profiles and their relationship in normal subjects. Am. Heart J. 126:419-426, 1993.

137. Van de Werf, F., A. Boel, J. Geboers, J. Minten, J. Willems, H. De Geest and H. Kesteloot. Diastolic properties of the left ventricle in normal adults and in patients with third heart sounds. Circulation 69:1070-1078, 1984.

138. Gleason, W. L. and E. Braunwald. Studies on the first derivative of the ventricular pressure pulse in man. J. Clin. Invest. 41:80-91, 1962. 
Table 1. Model equations.

\begin{tabular}{|c|c|c|}
\hline \multicolumn{3}{|c|}{ 1D Vessels } \\
\hline $\begin{array}{l}(\mathrm{T} 1) \\
(\mathrm{T} 2) \\
(\mathrm{T} 3) \\
(\mathrm{T} 4)\end{array}$ & $\begin{array}{c}\frac{\partial A}{\partial t}+\frac{\partial A u}{\partial x}=0 \\
\frac{\partial u}{\partial t}+u \frac{\partial u}{\partial x}+\frac{1}{\rho} \frac{\partial p}{\partial x}=\frac{-\xi \pi \mu}{\rho} \frac{u}{A} \\
p-p_{\text {ext }}=\frac{2 \rho c_{0}^{2}}{b}\left[\left(\frac{A}{A_{0}}\right)^{b / 2}-1\right]+\frac{\Gamma}{A \sqrt{A}} \frac{\partial A}{\partial t}+P_{0} \\
b=2 \rho c_{0}^{2} /\left(P_{0}-P_{\text {collapse }}\right)\end{array}$ & $\begin{array}{l}A, u, p, \text { cross-sectional area, velocity, pressure } \\
\rho, \text { blood density }\left(1.06 \mathrm{~g} / \mathrm{cm}^{3}\right) \\
\mu, \text { blood viscosity }(0.035 \text { poise }) \\
\xi \text {, viscous friction constant }\left(22 \mathrm{~cm}^{3} / \mathrm{g}\right)^{123} \\
p_{\text {ext }} \text {, external pressure }(0.0 \mathrm{mmHg}) \\
A_{0} \text {, reference cross-sectional area } \\
c_{0} \text {, reference wave speed } \\
P_{0} \text {, reference pressure } \\
\Gamma \text {, coefficient of wall viscosity } \\
P_{\text {collapse, collapse pressure }(-10 \mathrm{mmHg})}\end{array}$ \\
\hline \multicolumn{3}{|c|}{ Heart Chambers } \\
\hline $\begin{array}{l}\text { (T5) } \\
\text { (T6) } \\
\text { (T7) } \\
\text { (T9) } \\
\text { (T10) } \\
\text { (T11) }\end{array}$ & $\begin{array}{c}p_{\mathrm{pc}}=\kappa_{\mathrm{pc}} \exp \left[\left(v_{\mathrm{pc}}-V_{0, \mathrm{pc}}\right) / \Phi_{\mathrm{pc}}\right] \\
E_{\mathrm{nat}}=E_{\mathrm{fw}} E_{\mathrm{sep}} /\left(E_{\mathrm{fw}}+E_{\mathrm{sep}}\right)-\mu_{\mathrm{Av}} q_{\mathrm{v}} \\
E_{\mathrm{sep}}=\kappa_{\mathrm{L}} E_{\mathrm{fv}, \mathrm{L}}+\kappa_{\mathrm{R}} E_{\mathrm{fw}, \mathrm{R}} \\
p=p_{\mathrm{pc}}+E_{\mathrm{nat}}\left(v-V_{p=0}\right)-R_{\mathrm{s}} q+\frac{E_{\mathrm{nat}}}{E_{\text {sep }}} p^{*} \\
E_{\mathrm{fw}}=k\left[g_{1} /\left(1+g_{1}\right)\right]\left[g_{2} /\left(1+g_{2}\right)\right]+E_{\text {min }} \\
g_{1}=\left(\frac{t-t_{\text {onset }}}{\tau_{1}}\right)^{m_{1}}, \quad g_{2}=\left(\frac{t-t_{\text {onset }}}{\tau_{2}}\right)^{m_{2}} \\
k=\left(E_{\mathrm{fw}}^{\text {max }}-E_{\mathrm{fw}}^{\text {min }}\right) / \max \left[\left(\frac{g_{1}}{1+g_{1}}\right)\left(\frac{g_{2}}{1+g_{2}}\right)\right]\end{array}$ & $\begin{array}{l}p_{\mathrm{pc}} / v_{\mathrm{pc}}, \text { pericardial pressure / volume } \\
K_{\mathrm{pc}} / V_{0, \mathrm{pc}} / \Phi_{\mathrm{pc}}, \text { constants for pericardium } \\
E_{\mathrm{nat}} / E_{\mathrm{sep}}, \text { native/septal elastance } \\
E_{\mathrm{fw}}, \text { free wall elastance } \\
v / q \text {, chamber volume / outflow } \\
\mu_{\mathrm{AV}} \text {, atrioventricular plane piston constant } \\
V_{p=0} \text {, residual (zero pressure) volume } \\
p^{*}, \text { pressure in contralateral chamber } \\
R_{\mathrm{s}}=K_{\mathrm{s}} E_{\text {nat }}\left(v-V_{p=0}\right) \text {, source resistance } \\
\kappa, \text { septal elastance constant (L/R subscripts in } \\
\text { Eq. T7 refer to left/right atria or ventricles) } \\
\tau_{1} / \tau_{2}, \text { contraction / relaxation time offset } \\
m_{1} / m_{2}, \text { contraction / relaxation rate constant } \\
E_{\mathrm{fw}}^{\min }, E_{\mathrm{fw}}^{\text {max }}, \text { minimum/maximum } E_{\mathrm{fw}}\end{array}$ \\
\hline \multicolumn{3}{|c|}{ Valves } \\
\hline $\begin{array}{l}(\mathrm{T} 12) \\
(\mathrm{T} 13) \\
(\mathrm{T} 14) \\
(\mathrm{T} 15)\end{array}$ & $\begin{array}{c}\Delta p=B q|q|+L d q / d t \\
B=\rho /\left(2 A_{\text {eff }}^{2}\right), \quad L=\rho l_{\text {eff }} / A_{\text {eff }} \\
A_{\text {eff }}(t)=\left[A_{\text {eff,max }}-A_{\text {eff,min }}\right] \zeta(t)+A_{\text {eff,min }} \\
\frac{d \zeta}{d t}=K_{\mathrm{vo}}(1-\zeta) \Delta p, \quad \frac{d \zeta}{d t}=K_{\mathrm{vc}} \zeta \Delta p\end{array}$ & $\begin{array}{l}\Delta p / q \text {, transvalvular pressure difference / flow } \\
B / L \text {, Bernoulli resistance / inertance } \\
A_{\text {eff, }} \text { effective valve orifice area } \\
l_{\text {eff, effective valve orifice length }} \\
\zeta \text {, valve state }(0 \leq \zeta \leq 1) \\
K_{\mathrm{vo}}, \text { valve opening rate coefficient } \\
K_{\mathrm{vc}} \text {, valve closing rate coefficient }\end{array}$ \\
\hline \multicolumn{3}{|c|}{ Generic/Hepatic Vascular Beds } \\
\hline (T16) & $R_{\mathrm{vb}}=\left\{\begin{array}{cl}R_{0}\left(\frac{p_{\mathrm{tm} 0}-P_{\mathrm{tf}}}{\left.p_{\mathrm{tm}}-P_{\mathrm{tf}}\right)},\right. & p_{\mathrm{tm}}>P_{\mathrm{zf}} \\
\infty, & p_{\mathrm{tm}} \leq P_{\mathrm{zf}}\end{array}\right.$ & $\begin{array}{l}p_{\mathrm{tm}}=p-p_{\mathrm{ext}} \text {, transmural pressure } \\
P_{\mathrm{zf}}, \text { zero-flow pressure } \\
R_{\mathrm{vb}}, \text { microvascular resistance } \\
R_{0}, \text { reference resistance }\end{array}$ \\
\hline \multicolumn{3}{|c|}{ Coronary Vascular Beds } \\
\hline $\begin{array}{l}(\mathrm{T} 17) \\
(\mathrm{T} 18) \\
(\mathrm{T} 19)\end{array}$ & $\begin{array}{c}V_{i}(t)=V_{0, i}+\int_{0}^{t} C_{i} \frac{d p_{t m, i}}{d t^{\prime}} d t^{\prime} \\
R_{i}(t)=R_{0, i} V_{0, i}^{2} / V_{i}^{2} \\
R_{m}(t)=R_{0, m}\left[0.75 V_{0,1}^{2} / V_{1}^{2}+0.25 V_{0,2}^{2} / V_{2}^{2}\right]\end{array}$ & $\begin{array}{l}C_{i} \text {, intramyocardial compliance, } i=1,2 \\
V_{i}, \text { compliant compartment volume } \\
p_{t m, i}=p-p_{\text {im }}, \text { transmural pressure, where } p_{i m} \text { is } \\
\text { intramyocardial pressure } \\
R_{i}, R_{m} \text {, intramyocardial resistances }\end{array}$ \\
\hline
\end{tabular}


Table 2. Coefficients used in Eq. (T3) for calculation of wave speed for the adult model, along with the range of $c_{0}$ values in the respective 1D vascular networks and published reference values.

\begin{tabular}{lccccc}
\hline Vessel Type & $\begin{array}{c}k_{1} \\
10^{6} \mathrm{~g} / \mathrm{s}^{2} / \mathrm{cm}\end{array}$ & $\begin{array}{c}k_{2} \\
\mathrm{~cm}^{-1}\end{array}$ & $\begin{array}{c}k_{3} \\
10^{4} \mathrm{~g} / \mathrm{s}^{2} / \mathrm{cm}\end{array}$ & $\begin{array}{c}c_{0} \text { range } \\
\mathrm{cm} / \mathrm{s}\end{array}$ & $\begin{array}{c}\text { Reference values } \\
\text { (location) }\end{array}$ \\
\hline Systemic Arteries & 3.00 & -9 & 33.7 & $461-1021$ & 441 (AoRt) ${ }^{124,125}$ \\
Systemic Veins & 0.60 & -5 & 2.8 & $141-526$ & 115 (IVC) \\
Pulmonary Arteries & 1.30 & -7 & 12.2 & $277-526$ & 260 (RPA) \\
Pulmonary Veins & 0.29 & -5 & 2.1 & $125-260$ & - \\
Coronary Arteries & 20.00 & -22.5 & 86.5 & $789-1308$ & 860 (LAD) ${ }^{127}$ \\
Coronary Veins & 4.44 & -22.5 & 19.2 & $348-470$ & - \\
\hline
\end{tabular}

Abbreviations: AoRt, aortic root; IVC, inferior vena cava; LAD, left anterior descending artery; RPA, right pulmonary artery 
Table 3. Heart chamber parameter values.

\begin{tabular}{|c|c|c|c|c|c|}
\hline & & LV & $\mathrm{RV}$ & LA & RA \\
\hline$E_{\mathrm{fw}}^{\max }$ & $\mathrm{mmHg} / \mathrm{mL}$ & 2.8 & 0.45 & 0.13 & 0.09 \\
\hline$E_{\mathrm{fw}}^{\min }$ & $\mathrm{mmHg} / \mathrm{mL}$ & 0.070 & 0.035 & 0.09 & 0.045 \\
\hline$V_{p=0}$ & $\mathrm{~mL}$ & 10 & 40 & 3 & 7 \\
\hline$V_{t=0}$ & $\mathrm{~mL}$ & 136 & 172 & 71 & 67 \\
\hline$K_{\mathrm{S}}$ & $10^{-3} \mathrm{~s} / \mathrm{mL}$ & 0.5 & 1.0 & 0.25 & 0.5 \\
\hline$\tau_{1}$ & $\mathrm{~s}$ & 0.215 & 0.215 & 0.042 & 0.042 \\
\hline$\tau_{2}$ & $s$ & 0.362 & 0.362 & 0.138 & 0.138 \\
\hline$m_{1}$ & - & 1.32 & 1.32 & 1.99 & 1.99 \\
\hline$m_{2}$ & - & 21.9 & 21.9 & 11.2 & 11.2 \\
\hline$\kappa$ & - & 6 & 6 & 2 & 2 \\
\hline$\mu_{\mathrm{AV}}$ & g. $\mathrm{cm}^{-7} \cdot \mathrm{s}^{-1}$ & 0 & 0 & 0.050 & 0.033 \\
\hline$t_{\text {onset }}$ & $\mathrm{s}$ & 0 & 0 & 0.65 & 0.65 \\
\hline
\end{tabular}

Abbreviations: LA, left atrium; LV, left ventricle; RA, right atrium; RV, right ventricle. See Table 1 in the main manuscript for a description of chamber parameters. Note that $V_{t=0}$ is initial volume while $V_{p=0}$ is the pressure-axis intercept of the pressure-volume relation. 
Table 4. Heart valve parameter values.

\begin{tabular}{llllll}
\hline & & AV & PV & MV & TV \\
\hline$A_{\text {eff,max }}$ & $\mathrm{cm}^{2}$ & 4.9 & 5.7 & 5.1 & 6.0 \\
$A_{\text {eff,min }}$ & $\mathrm{cm}^{2}$ & 0.0 & 0.0 & 0.0 & 0.0 \\
$l_{\text {eff }}$ & $\mathrm{cm}^{2}$ & 1.0 & 1.5 & 2.0 & 2.0 \\
$K_{\mathrm{vo}}$ & $\mathrm{cm}^{2} \mathrm{~s}^{2} \mathrm{~g}^{-1}$ & 0.02 & 0.02 & 0.02 & 0.03 \\
$K_{\mathrm{vc}}$ & $\mathrm{cm}^{2} \mathrm{~s}^{2} \mathrm{~g}^{-1}$ & 0.02 & 0.02 & 0.04 & 0.04 \\
\hline
\end{tabular}

Abbreviations: $\mathrm{AV}$, aortic valve; MV, mitral valve; PV, pulmonary valve; TV, tricuspid valve. See Table 1 for a description of valve parameters. 
Table 5: Distribution of vascular compliance.

\begin{tabular}{lcc}
\hline & $\begin{array}{c}\text { Compliance } \\
(\mathrm{mL} / \mathrm{mmHg})\end{array}$ & Reference \\
Entire circulation & 170 & 128 \\
Systemic arteries & 1.7 & 129 \\
Systemic veins (incl. liver) & 146 & 130 \\
Liver & 54 & 131 \\
Pulmonary Arteries & 6.7 & 132 \\
Pulmonary Veins & 15.8 & 132 \\
\hline
\end{tabular}


Table 6: Comparison of model haemodynamics with in vivo reference data.

\begin{tabular}{|c|c|c|c|}
\hline Parameter & Units & Model & Reference \\
\hline Heart Rate & beats/min & 75 & $71(53,89)^{131}$ \\
\hline Cardiac Output & $\mathrm{L} / \mathrm{min}$ & 6.2 & $6.5(3.6,9.4)^{131}$ \\
\hline SVR & $\mathrm{mmHg} . \mathrm{s} / \mathrm{mL}$ & 0.90 & $0.80(0.5,1.1)^{131}$ \\
\hline PVR & $\mathrm{mmHg} . \mathrm{s} / \mathrm{mL}$ & 0.06 & $0.06(0.02,0.09)^{131}$ \\
\hline \multicolumn{4}{|c|}{ Heart chamber volumes } \\
\hline LV (max) & $\mathrm{mL}$ & 141 & $150(83,218)^{133}$ \\
\hline $\mathrm{RV}(\max )$ & $\mathrm{mL}$ & 156 & $173(78,256)^{133}$ \\
\hline LA (max) & $\mathrm{mL}$ & 115 & $97( \pm 27)^{133}$ \\
\hline $\mathrm{RA}(\max )$ & $\mathrm{mL}$ & 110 & $101(37,177)^{134}$ \\
\hline $\mathrm{LV}(\mathrm{EF})$ & - & 0.60 & $0.68(0.57,0.81)^{133}$ \\
\hline $\mathrm{RV}(\mathrm{EF})$ & - & 0.53 & $0.57(0.47,0.78)^{133}$ \\
\hline $\mathrm{LA}(\min )$ & $\mathrm{mL}$ & 75 & $44( \pm 13)^{133}$ \\
\hline $\mathrm{RA}(\min )$ & $\mathrm{mL}$ & 58 & $50(15,92)^{134}$ \\
\hline \multicolumn{4}{|l|}{ Pressure } \\
\hline LA (mean) & $\mathrm{mmHg}$ & 8 & $8(2,12)^{131}$ \\
\hline RA (mean) & $\mathrm{mmHg}$ & 4 & $5(0.2,9)^{131}$ \\
\hline AoRt (mean) & $\mathrm{mmHg}$ & 97 & $97(80,113)^{131}$ \\
\hline AoRt (pulse) & $\mathrm{mmHg}$ & 38 & $39(24,54)^{131}$ \\
\hline PT (mean) & $\mathrm{mmHg}$ & 15 & $15(10,19)^{131}$ \\
\hline PT (pulse) & $\mathrm{mmHg}$ & 10 & $11(6,17)^{131}$ \\
\hline Portal (mean) & $\mathrm{mmHg}$ & 8 & $6(3,10)^{135}$ \\
\hline \multicolumn{4}{|l|}{ E/A Ratios } \\
\hline Mitral & - & 2.1 & $2.5(1.5,3.4)^{136}$ \\
\hline Tricuspid & - & 1.8 & $2.3(1.4,3.3)^{136}$ \\
\hline \multicolumn{4}{|c|}{ Pressure Rate (dp/dt) } \\
\hline $\operatorname{LV}(\max )$ & $\mathrm{mmHg} / \mathrm{s}$ & 1527 & $1915( \pm 410)^{137}$ \\
\hline LV (min) & $\mathrm{mmHg} / \mathrm{s}$ & -2200 & $-2296( \pm 530)^{137}$ \\
\hline $\mathrm{RV}(\max )$ & $\mathrm{mmHg} / \mathrm{s}$ & 257 & $248(223,296)^{138}$ \\
\hline $\mathrm{RV}(\min )$ & $\mathrm{mmHg} / \mathrm{s}$ & -232 & - \\
\hline
\end{tabular}

Reference data given as a mean, with range or standard deviation in parentheses. 
Table 7: Mechanisms underlying waves indicated in Figs. 5 and 6.

\begin{tabular}{|c|c|c|c|}
\hline Wave & $\mathrm{P}$ & $\mathrm{U}$ & Description \\
\hline \multicolumn{4}{|c|}{ Aortic Root / Carotid / Brachial / Main Pulmonary Arteries } \\
\hline $\mathrm{FCW}_{\mathrm{ee}}$ & $\uparrow$ & $\uparrow$ & Early ejection (ee) wave arising from ventricular contraction \\
\hline BCW & $\uparrow$ & $\downarrow$ & Backward compression wave arising from vascular reflection of $\mathrm{FCW}_{\mathrm{ee}}$ \\
\hline $\mathrm{FEW}_{\mathrm{IS}}$ & $\downarrow$ & $\downarrow$ & Late systolic (Is) wave arising from ventricular relaxation \\
\hline $\mathrm{FCW}_{\mathrm{vc}}$ & $\uparrow$ & $\uparrow$ & Wave associated with valve closure (vc) and the dicrotic notch \\
\hline \multicolumn{4}{|c|}{ Carotid / Brachial } \\
\hline $\mathrm{FEW}_{\mathrm{ms}}$ & $\downarrow$ & $\downarrow$ & $\begin{array}{l}\text { Mid-systolic (ms) re-reflection of the BCW due to impedance mismatching in } \\
\text { the backward direction. }\end{array}$ \\
\hline \multicolumn{4}{|c|}{ Vena Cavae / Pulmonary Veins } \\
\hline $\mathrm{BEW}_{\mathrm{ar}}$ & $\downarrow$ & $\uparrow$ & Aspirating wave caused by atrial relaxation (ar) \\
\hline BEW $_{\text {ada }}$ & $\downarrow$ & $\uparrow$ & Aspirating wave caused by atrioventricular plane acceleration (ada) \\
\hline $\mathrm{BCW}_{\text {add }}$ & $\uparrow$ & $\downarrow$ & Halting wave caused by atrioventricular plane descent deceleration (add) \\
\hline $\mathrm{BEW}_{\mathrm{vd}}$ & $\downarrow$ & $\uparrow$ & Aspirating wave caused by ventricular diastole (vd) after mitral valve opening \\
\hline $\mathrm{BCW}_{\mathrm{ac}}$ & $\uparrow$ & $\downarrow$ & Decelerating wave caused by atrial contraction (ac) \\
\hline
\end{tabular}

Wave abbreviations: BCW, backward compression wave; BEW, backward expansion wave; FCW, forward compression wave; FEW, forward expansion wave 
Table 8: Sensitivity of major waves to changes in cardiac function and chamber interactions.

\begin{tabular}{|c|c|c|c|c|c|c|c|c|}
\hline & $\begin{array}{l}\text { AoRt } \\
\text { FCW }_{\mathrm{ee}}\end{array}$ & $\begin{array}{l}\text { AoRt } \\
\text { FEW }_{\text {ls }}\end{array}$ & $\begin{array}{c}\text { MPA } \\
\text { FCW }_{\text {ee }}\end{array}$ & $\begin{array}{l}\text { MPA } \\
\text { FEW }_{\text {Is }}\end{array}$ & $\begin{array}{c}\text { IVC } \\
\mathrm{BCW}_{\mathrm{ac}}\end{array}$ & $\begin{array}{c}\text { IVC } \\
\text { BEW }_{a r}\end{array}$ & $\begin{array}{l}\text { LIPV } \\
\text { BCW }_{\mathrm{ac}}\end{array}$ & $\begin{array}{l}\text { LIPV } \\
\text { BEW }_{\mathrm{ar}}\end{array}$ \\
\hline$L V E_{f w}^{\max }-50 \%$ & $-60 \%$ & $56 \%$ & $-17 \%$ & $-4 \%$ & $-16 \%$ & $-17 \%$ & $19 \%$ & $38 \%$ \\
\hline $\mathrm{RV} E_{\mathrm{fw}}^{\max }-50 \%$ & $-24 \%$ & $-5 \%$ & $-60 \%$ & $-6 \%$ & $34 \%$ & $43 \%$ & $-14 \%$ & $-20 \%$ \\
\hline LA $E_{f w}^{\max }-50 \%$ & $-8 \%$ & $-2 \%$ & $-8 \%$ & $-5 \%$ & $-11 \%$ & $-23 \%$ & $-95 \%$ & $38 \%$ \\
\hline RA $E_{f w}^{\max }-50 \%$ & $-11 \%$ & $-3 \%$ & $-12 \%$ & $-15 \%$ & $-99 \%$ & $-99 \%$ & $-22 \%$ & $-25 \%$ \\
\hline$L V E_{f w}^{\min }+50 \%$ & $-15 \%$ & $-6 \%$ & $-15 \%$ & $4 \%$ & $-7 \%$ & $-2 \%$ & $45 \%$ & $57 \%$ \\
\hline $\mathrm{RV} E_{\mathrm{fw}}^{\mathrm{min}}+50 \%$ & $-14 \%$ & $-4 \%$ & $-23 \%$ & $-26 \%$ & $46 \%$ & $48 \%$ & $-7 \%$ & $-6 \%$ \\
\hline LA $E_{\mathrm{fw}}^{\mathrm{min}}+50 \%$ & $-3 \%$ & $0 \%$ & $-2 \%$ & $3 \%$ & $0 \%$ & $0 \%$ & $-94 \%$ & $-94 \%$ \\
\hline $\mathrm{RA} E_{\mathrm{fw}}^{\mathrm{min}}+50 \%$ & $-6 \%$ & $-1 \%$ & $-8 \%$ & $-8 \%$ & $-77 \%$ & $-79 \%$ & $-16 \%$ & $-14 \%$ \\
\hline $\mathrm{RV} \mathrm{V}_{0}+150 \mathrm{~mL}$ & $-30 \%$ & $-9 \%$ & $-29 \%$ & $-39 \%$ & $-40 \%$ & $-44 \%$ & $-35 \%$ & $-39 \%$ \\
\hline$\kappa=0$ & $13 \%$ & $-9 \%$ & $-17 \%$ & $-2 \%$ & $-11 \%$ & $-10 \%$ & $-20 \%$ & $-25 \%$ \\
\hline$\mu=0$ & $-4 \%$ & $0 \%$ & $-5 \%$ & $-17 \%$ & $-13 \%$ & $-15 \%$ & $-17 \%$ & $-21 \%$ \\
\hline
\end{tabular}

Values indicate the percentage change of the specified wave peak intensity magnitude for the specified input parameter change. Abbreviations: ac, atrial contraction; AoRt, aortic root; ar, atrial relaxation; $\mathrm{BCW}$, backward compression wave; $\mathrm{BEW}$, backward compression wave; ee, early ejection; FCW, forward compression wave; FEW, forward expansion wave; IVC, inferior vena cava; MPA, main pulmonary artery; LA, left atrium; LIPV, left inferior pulmonary vein; Is, late systolic; LV, left ventricle; RA, right atrium; RV, right ventricle; $\kappa$, septal interaction constant (for all chambers); $\mu$, atrioventricular plane velocity coefficient (mitral and tricuspid). See Table 1 for further information about input parameters and Table 7 for wave definitions. 


\section{Figure Captions}

Fig. 1. (A) Schematic of the atrium/ventricle model. Illustrations of (B) heart chamber interaction via the pericardium, where a volume increase in one heart chamber (RV in this case) causes an increased pericardial pressure $\left(p_{\mathrm{pc}}\right)$ that impinges on other heart chambers; (C) interactions between contralateral atria or ventricles due to septal bulging and displacement of volume; (D) atrio-ventricular interaction, whereby descent of the atrioventricular plane aids atrial filling. Abbreviations: A, atrial; $B$, Bernoulli valve resistance; $E$, elastance; AV, atrioventricular; L, valve inertance; LA, left atrium; LV, left ventricle; $R$, source resistance; RA, right atrium; RV, right ventricle; $\mathrm{V}$, ventricular.

Fig. 2. (A) The generic vascular bed model; (B) the hepatic vascular bed model enabling arterial and portal venous inlets; and (C) the coronary vascular bed model, representing subepicardial, midwall and subendocardial layers, along with the influence of intramyocardial pressure. Symbols are defined in Table 1 and the main text.

Fig. 3. One-dimensional vascular networks: (A) systemic arteries, (B) systemic veins, (C) pulmonary arteries, (D) pulmonary veins, (E) ventricular outflow tract segments, (F) portal veins, $(G)$ coronary arteries, $(H)$ coronary veins, $(I)$ head/neck arteries, $(J)$ head/neck veins.

Fig. 4. Comparison of published human flow and pressure waveforms $s^{1,82-102}$ with model generated waveforms. Numbers next to in vivo waveforms refer to source references; asterisks indicate that a measured velocity waveform has been has been converted to a flow waveform by assuming the same peak flow value as in the model. 
Fig. 5. Model-derived pressure ( $\mathrm{P}$, black line), velocity ( $U$, grey line) and wave intensity (WI) in the aortic root, common carotid artery and brachial artery. See Table 7 for definition of wave labels.

Fig. 6. Model-derived pressure ( $P$, black line), velocity ( $U$, grey line) and wave intensity (WI) in the main pulmonary artery, inferior vena cava and left inferior pulmonary vein. See Table 7 for definition of wave labels.

Fig. 7. Peak forward (black solid) and backward (red dashed) wave intensity along arteriovenous paths via the head (A), arm (B), leg (C), abdomen (D), left ventricular myocardium (E) and right inferior lung (F). Grey bands indicate microvascular beds in which wave effects were not accounted for. 1D segment label abbreviations are defined in Supplemental File 1. 
Fig. 1. (A) Schematic of the atrium/ventricle model. Illustrations of (B) heart chamber interaction via the pericardium, where a volume increase in one heart chamber (RV in this case) causes an increased pericardial pressure $\left(p_{\mathrm{pc}}\right)$ that impinges on other heart chambers; (C) interactions between contralateral atria or ventricles due to septal bulging and displacement of volume; (D) atrio-ventricular interaction, whereby descent of the atrioventricular plane aids atrial filling. Abbreviations: A, atrial; $B$, Bernoulli valve resistance; $E$, elastance; $A V$, atrioventricular; $L$, valve inertance; $L A$, left atrium; LV, left ventricle; $R$, source resistance; $\mathrm{RA}$, right atrium; $\mathrm{RV}$, right ventricle; $\mathrm{V}$, ventricular.

A

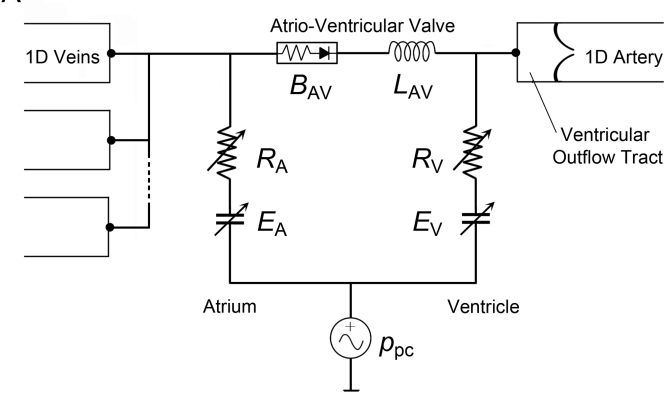

B

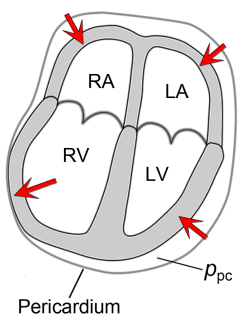

C

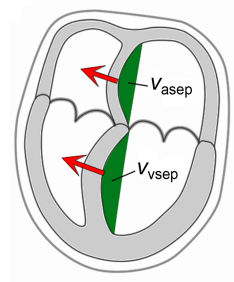

D

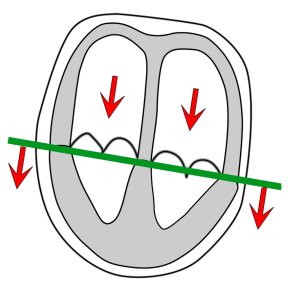


Fig. 2. (A) The generic vascular bed model; (B) the hepatic vascular bed model enabling arterial and portal venous inlets; and (C) the coronary vascular bed model, representing subepicardial, midwall and subendocardial layers, along with the influence of intramyocardial pressure. Symbols are defined in Table 1 and the main text.

A. Generic Vascular Bed

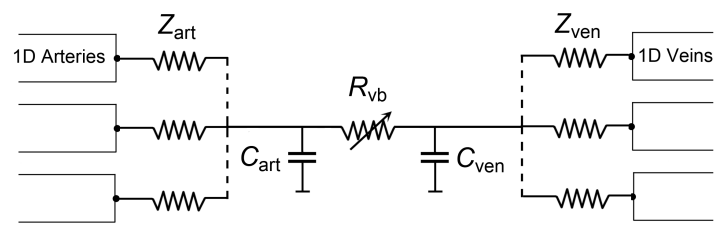

C. Coronary Vascular Bed

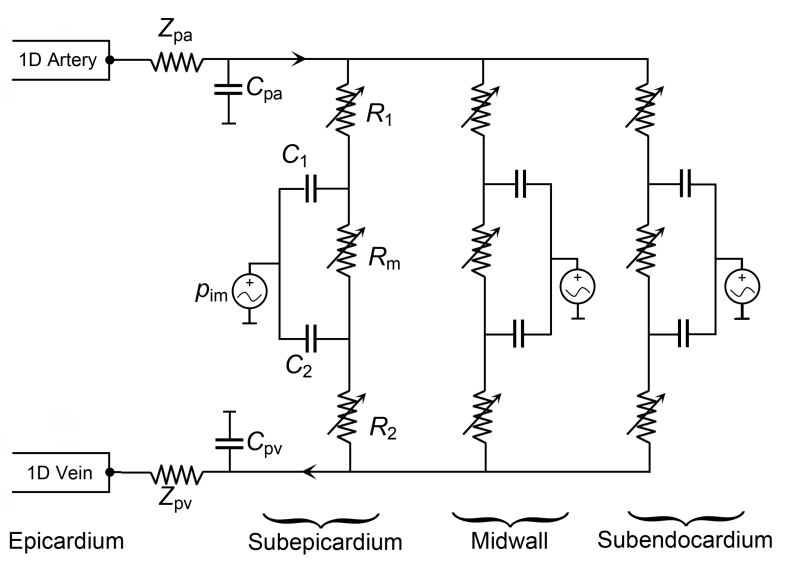

B. Hepatic Vascular Bed

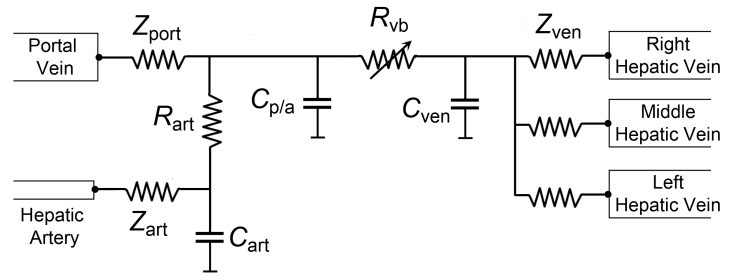


Fig. 3. One-dimensional vascular networks: (A) systemic arteries, (B) systemic veins, (C) pulmonary arteries, (D) pulmonary veins, (E) ventricular outflow tract segments, (F) portal veins, $(G)$ coronary arteries, $(H)$ coronary veins, $(I)$ head/neck arteries, $(J)$ head/neck veins.

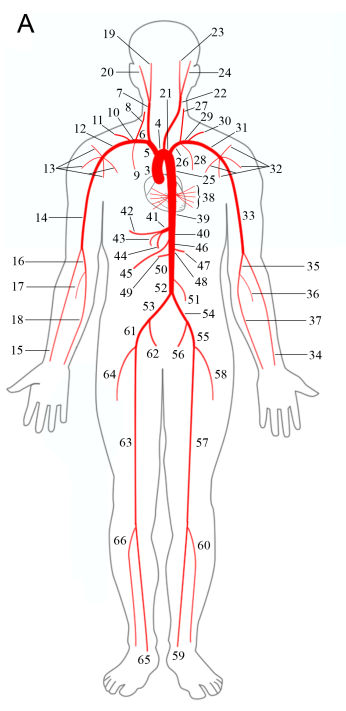

C

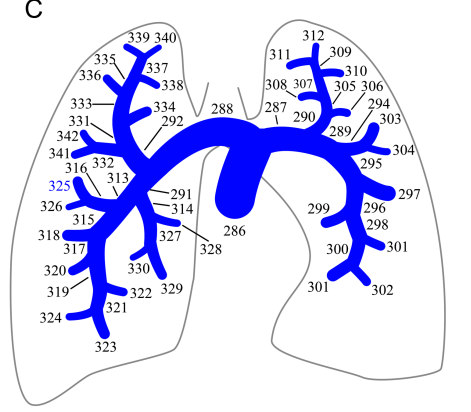

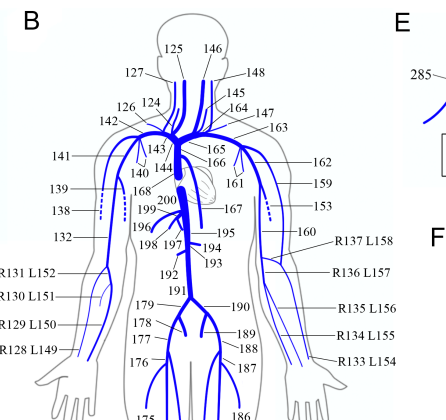

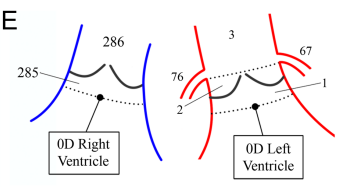

$\mathrm{F}$
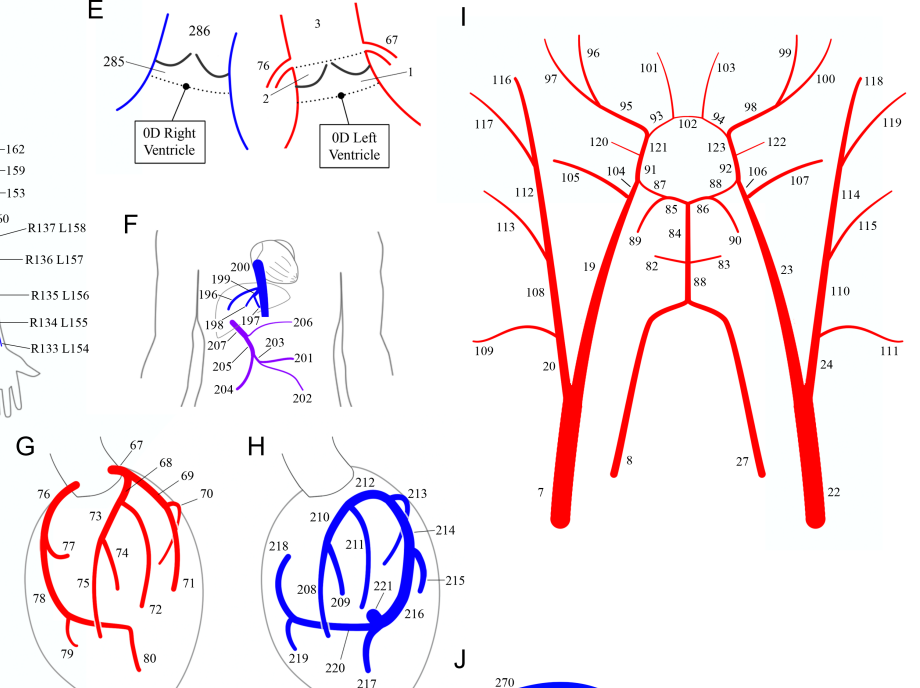

D
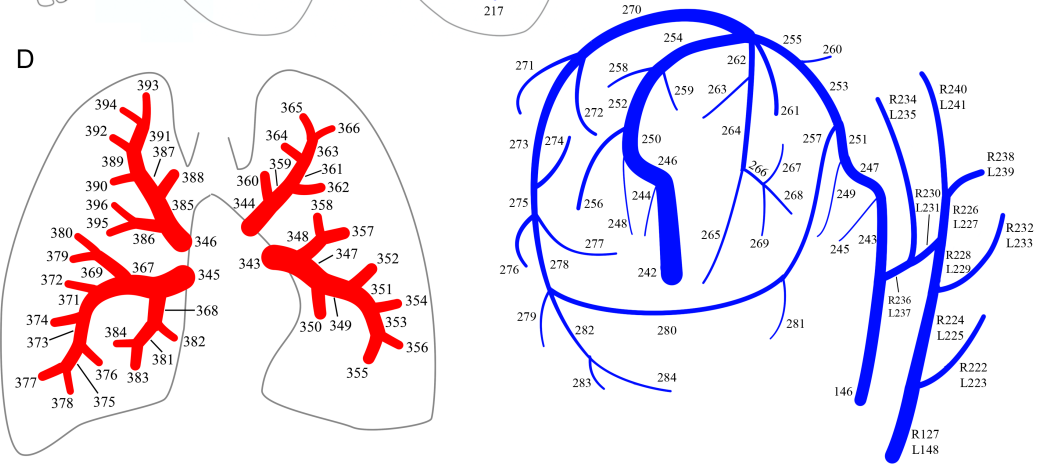
Fig. 4. Comparison of published human flow and pressure waveforms $s^{1,82-102}$ with model generated waveforms. Numbers next to in vivo waveforms refer to source references; asterisks indicate that a measured velocity waveform has been has been converted to a flow waveform by assuming the same peak flow value as in the model.
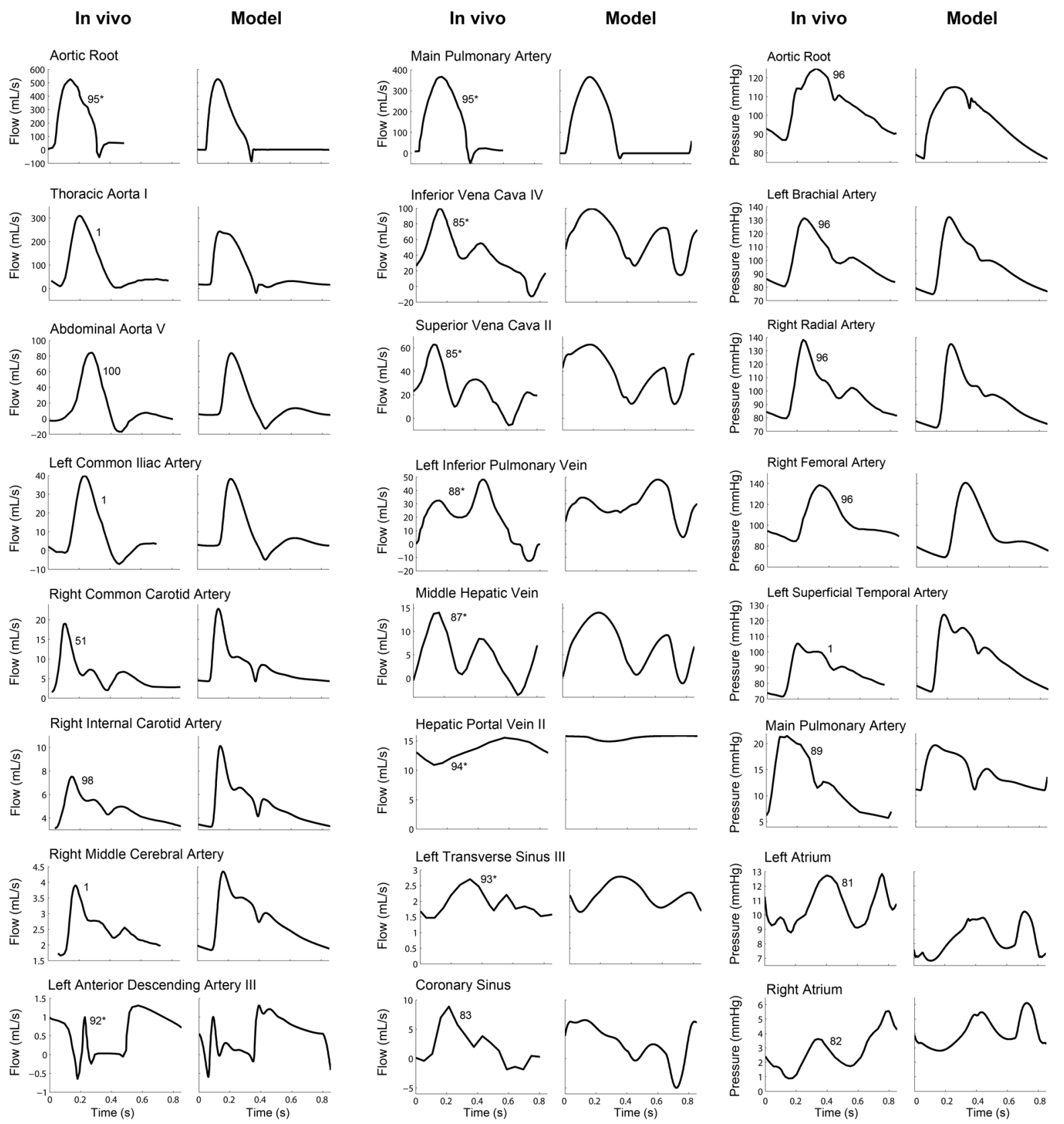
Fig. 5. Model-derived pressure ( $P$, black line), velocity ( $U$, grey line) and wave intensity (WI) in the aortic root, common carotid artery and brachial artery. See Table 7 for definition of wave labels.
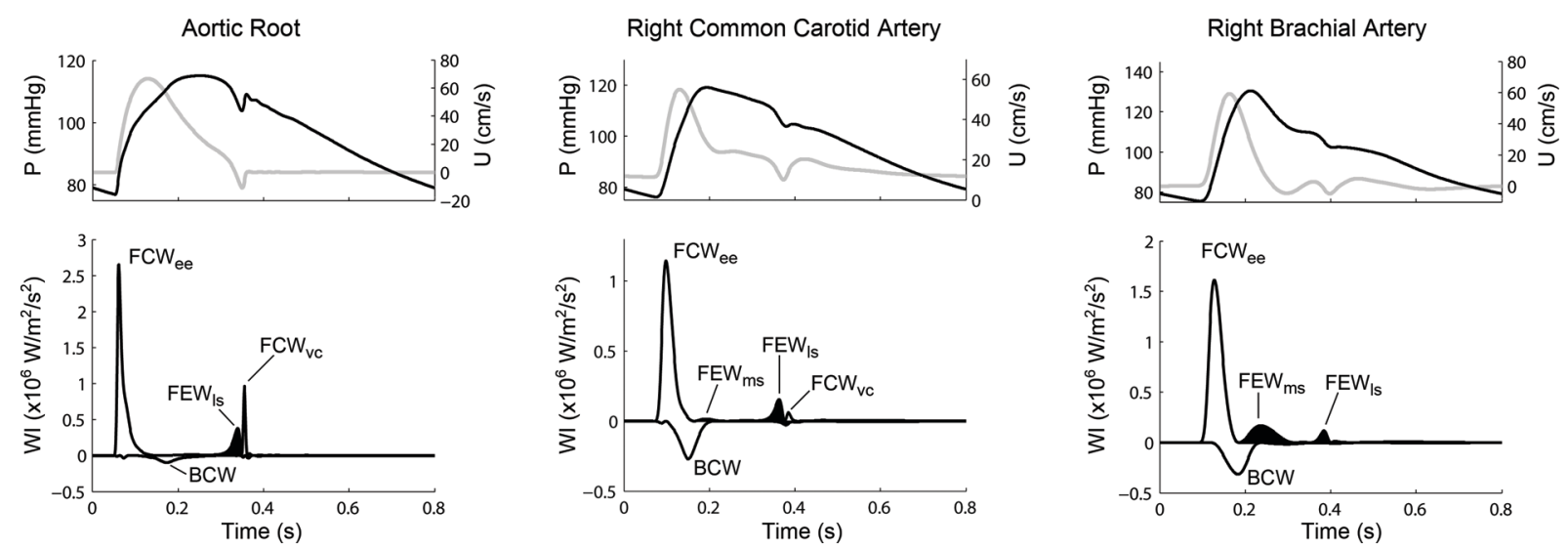
Fig. 6. Model-derived pressure ( $\mathrm{P}$, black line), velocity ( $U$, grey line) and wave intensity (WI) in the main pulmonary artery, inferior vena cava and left inferior pulmonary vein. See Table 7 for definition of wave labels.
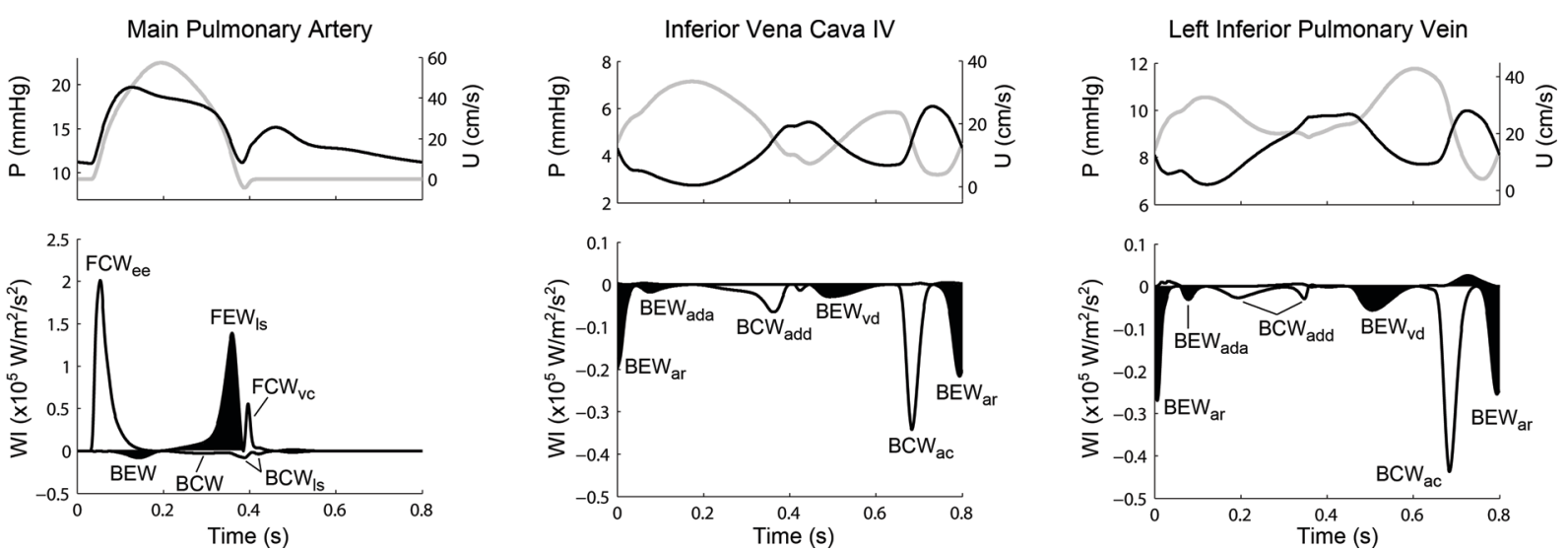
Fig. 7. Peak forward (black solid) and backward (red dashed) wave intensity along arteriovenous paths via the head (A), arm (B), leg (C), abdomen (D), left ventricular myocardium (E) and right inferior lung (F). Grey bands indicate microvascular beds in which wave effects were not accounted for. 1D segment label abbreviations are defined in Supplemental File 1.
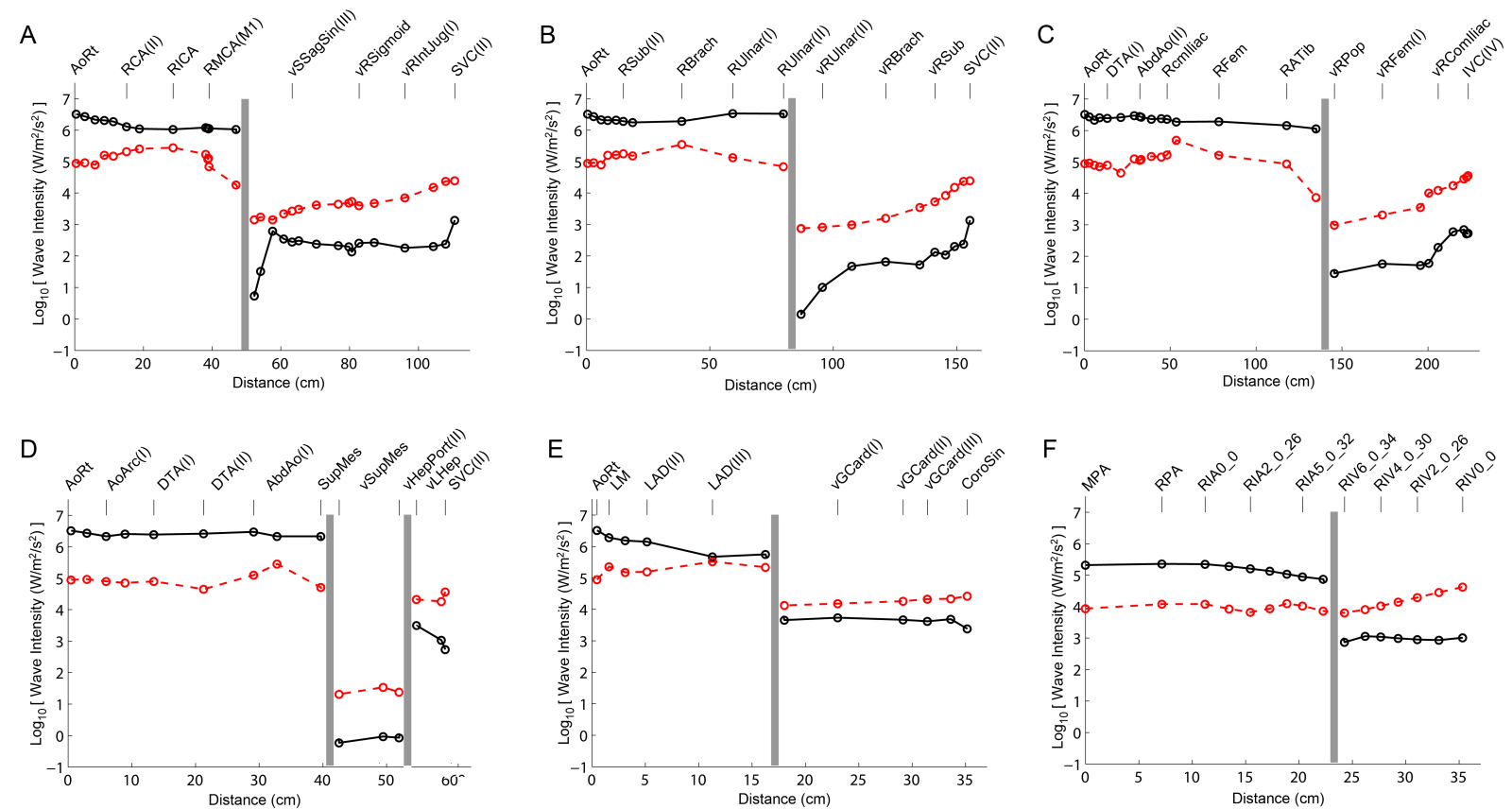


\section{University Library}

\section{- M M N E R VA A gateway to Melbourne's research publications}

Minerva Access is the Institutional Repository of The University of Melbourne

Author/s:

Mynard, JP;Smolich, JJ

Title:

One-Dimensional Haemodynamic Modeling and Wave Dynamics in the Entire Adult Circulation

Date:

2015-06-01

Citation:

Mynard, J. P. \& Smolich, J. J. (2015). One-Dimensional Haemodynamic Modeling and Wave Dynamics in the Entire Adult Circulation. ANNALS OF BIOMEDICAL ENGINEERING, 43 (6), pp.1443-1460. https://doi.org/10.1007/s10439-015-1313-8.

Persistent Link:

http://hdl.handle.net/11343/58855 